VESTÍGIOS - Revista Latino-Americana de Arqueologia Histórica

Volume 15 | Número 2 | Julho - Dezembro 2021

ISSN 1981-5875

ISSN (online) 2316-9699

RUMO A UMA ARQUEOLOGIA CRÍTICA

HACIA UMA ARQUEOLOGÍA CRÍTICA

TOWARD A CRITICAL ARCHAEOLOGY

Mark P. Leone

Parker B. Potter Jr.

Paul A. Shackel

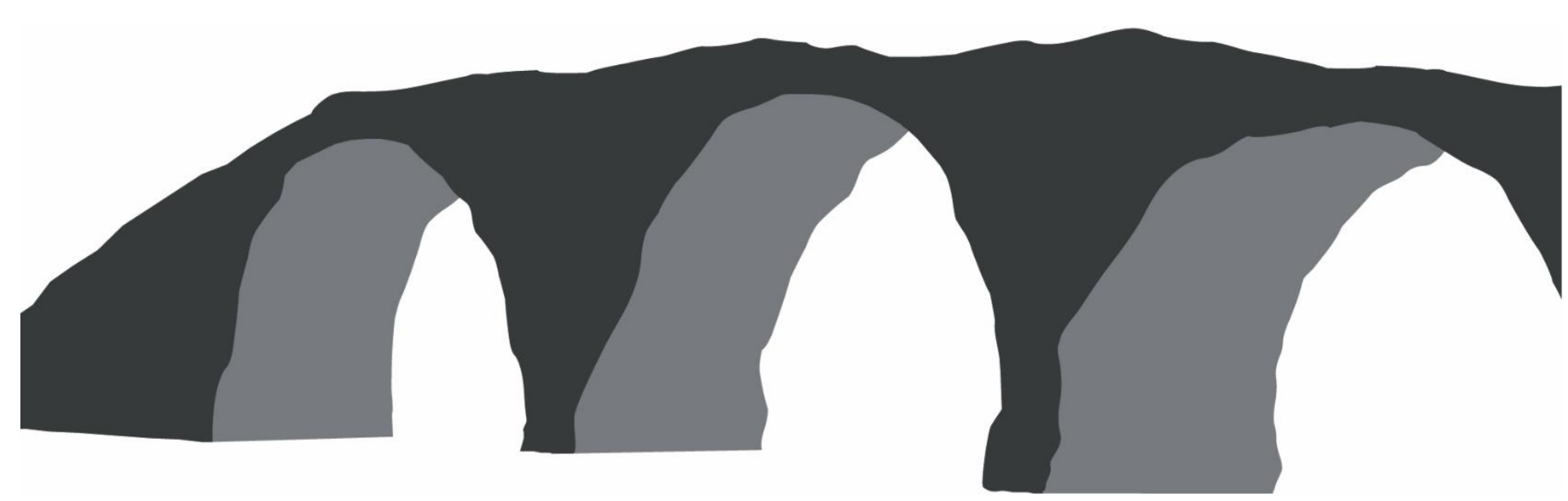




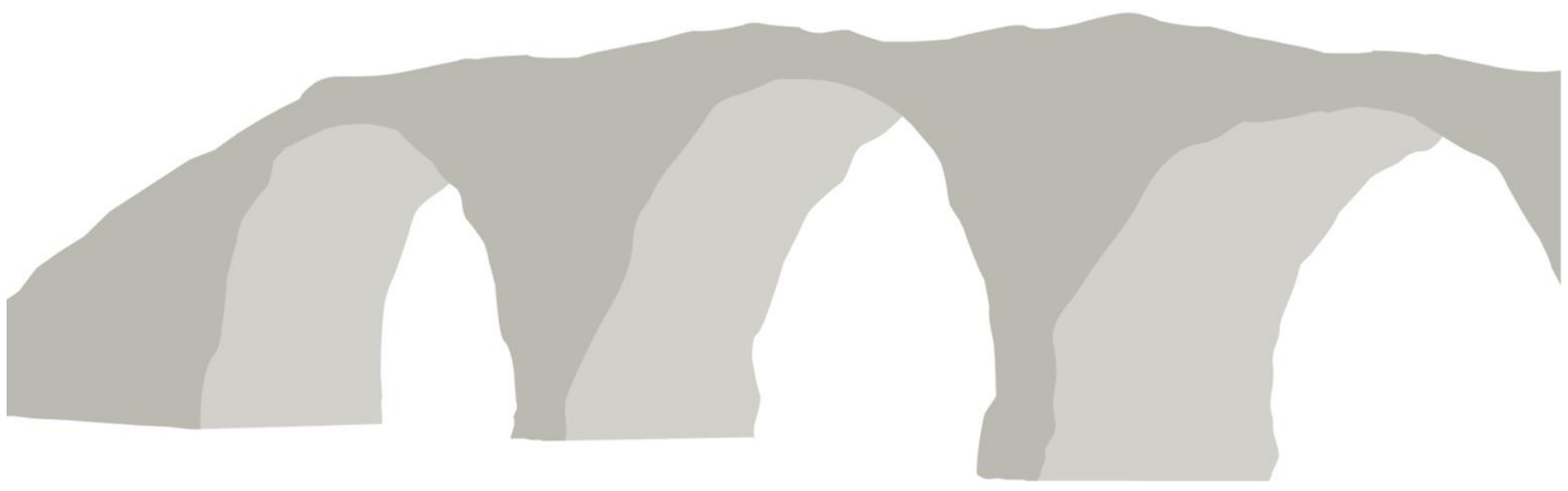

Publicação original:

Leone, M., Potter Jr., P. B., Shackel, P. A. (1987). Toward a Critical Archaeology. Current Anthropology, 28(3), p. 283-302

Republished with permission of University of Chicago Press - Journals, from Leone, M., Potter Jr., P. B., Shackel, P. A. (1987).

Toward a Critical Archaeology. Current Anthropology, 28(3), p. 283-302; permission conveyed through Copyright Clearance Center, Inc. 


\title{
RUMO A UMA ARQUEOLOGIA CRÍTICA ${ }^{1}$
}

\author{
HACIA UMA ARQUEOLOGÍA CRÍTICA
}

\section{TOWARD A CRITICAL ARCHAEOLOGY²}

\author{
Mark P. Leone ${ }^{3}$ \\ Parker B. Potter Jr. ${ }^{4}$
}

Paul A. Shackel ${ }^{5}$

\begin{abstract}
RESUMO
A Teoria Crítica - que se caracteriza essencialmente por um esforço para explorar e aumentar as percepções de Marx sobre a natureza do conhecimento da sociedade humana - vem sendo crescentemente aplicada às Ciências Humanas. Os arqueólogos são convidados a considerar a Teoria Crítica pela evidência de que a Arqueologia, em alguns ambientes, é usada para fins políticos, e pela crescente controvérsia sobre a propriedade e o controle de remanescentes e interpretações do passado. A Arqueologia Crítica assume que a interrelação entre a Arqueologia e a Política permitirá que os arqueólogos obtenham conhecimento menos contingentes sobre o passado e o presente. A maneira pela qual a Teoria Crítica pode ser aplicada à Arqueologia é ilustrada neste artigo por uma análise de dados de um projeto municipal conduzido em Annapolis, Maryland, o qual busca desmistificar a forma como o passado foi construído.
\end{abstract}

\footnotetext{
${ }^{1}$ Traduzido para português por Alex da Silva Martire. Pós-Doutorando no Programa de Pós-Graduação em Antropologia (FAFICH - UFMG). E-mail: alexmartire@gmail.com. ORCID: https://orcid.org/0000-0003-1744-3900.

${ }^{2}$ Este artigo é baseado nos resultados de escavações e/ou programas interpretativos em cinco sítios arqueológicos em Annapolis. Todos foram conduzidos por "Archaeology in Annapolis", que é codirigido por Richard J. Dent (University of Maryland, College Park), Mark P. Leone e Anne E. Yentsch (Historic Annapolis, Inc.). O projeto é um programa de pesquisa municipal de dez anos, patrocinado em conjunto pela Universidade de Maryland e pela Historic Annapolis, Inc., uma organização privada de preservação sem fins lucrativos de trinta e cinco anos para o condado de Annapolis e Anne Arundel. Além do apoio dessa organização e de fundos da cidade de Annapolis, a "Arqueologia em Annapolis" recebeu doações de muitas fontes para a escavação e interpretação desses locais. O local do Victualling Warehouse é propriedade do estado de Maryland e administrado pela Historic Annapolis, Inc.; fundos para sua escavação e interpretação vieram do Conselho de Humanidades de Maryland (Apoios 546, 601-E, 738-F). O trabalho na Hammond-Harwood House foi conduzido pela Historic Annapolis, Inc., sob contrato com a Hammond-Harwood House Association, proprietária da propriedade. A Pousada State House é propriedade de Paul Pearson e Historic Inns of Annapolis, e o trabalho lá foi financiado em parte pela National Geographic Society (Apoio 3116-85). A Shiplap House é propriedade de Donald O. Jackson, e o trabalho lá foi apoiado pelo Conselho de Humanidades de Maryland (Apoio 780-G). O sítio da Main Street é propriedade de uma parceria liderada por Paul Pearson, e essa parceria e o Conselho de Humanidades de Maryland (Apoio 842-G) apoiaram o trabalho lá. Outro trabalho interpretativo, que levou às perspectivas desenvolvidas neste artigo, foi apoiado pelo Comitê de Herança de Maryland e pelo National Endowment for the Humanities (Apoio GM-21645-83). Embora a Historic Annapolis, Inc., uma organização educacional e de preservação sem fins lucrativos, fundada em 1952 para preservar o atual National Historic Landmark District de Annapolis e sua história, tenha fornecido financiamento e compartilhado seus resultados de pesquisa com "Arqueologia em Annapolis", as opiniões e teorias dos autores não refletem necessariamente as opiniões da Historic Annapolis, Inc..

${ }^{3}$ Professor associado de Antropologia na University of Maryland (College Park, Md. 20742, EUA).

${ }^{4}$ Doutorando na Brown University e diretor do "Arqueologia em Público" da Historic Annapolis, Inc.

${ }^{5}$ Doutorando na Universidade Estadual de Nova York em Buffalo e arqueólogo de campo do programa "Arqueologia em Annapolis".
} 


\section{RESUMEN}

La teoría crítica, pensada esencialmente como un esfuerzo por explorar y aumentar la comprensión de Marx sobre la naturaleza del conocimiento en la sociedad humana, se está aplicando cada vez más a las ciencias humanas. En este articulo, se invita a los arqueólogos a considerar la teoría crítica para pensar como la arqueología en algunos escenarios, se utiliza con fines políticos para controlar las interpretaciones sobre el pasado. Consideramos desde una arqueología crítica, que ver la interrelación entre la arqueología y la política permitirá a los arqueólogos adquirir conocimientos menos circunstanciales. Nos proponemos ejemplificar como aplicar teoría crítica en arqueología, mediante el análisis de datos de un proyecto municipal realizado en Annapolis, Maryland. Estudio destinado a desmitificar la forma en que se construye el pasado.

\section{ABSTRACT}

Critical theory, essentially an effort to explore and add to Marx's insights into the nature of knowledge of human society, is increasingly being applied to the human sciences. Archaeologists are invited to consider critical theory by evidence that archaeology in some environments is used to serve political ends and by the growing controversy over the ownership and control of re- mains and interpretations of the past. The claim of a critical archaeology is that seeing the interrelationship between archaeology and politics will allow archaeologists to achieve less contingent knowledge. The way in which critical theory can be applied to archaeology is here illustrated by an analysis of data from a citywide project conducted in Annapolis, Marylanda project aimed at demystifying the way a past is constructed. 
A Teoria Crítica se caracteriza por um conjunto de tentativas variadas de adaptar as ideias de Marx à compreensão dos eventos e circunstâncias da vida do século XX que Marx não conhecia. Essa abordagem começou com a escola de filosofia de Frankfurt na década de 1920 e foi, em grande parte, um esforço para explorar e aumentar as percepções de Marx sobre a natureza do conhecimento da sociedade humana. Entre os membros do grupo de Frankfurt estão Adorno, Horkheimer, Benjamin e Marcuse; Lukacs e Gramsci, embora não sejam representantes da escola, também são importantes. A Teoria Crítica foi aplicada a uma variedade de áreas das ciências humanas e disciplinas humanísticas e agora está tendo um impacto na Arqueologia na GrãBretanha e nos Estados Unidos.

Uma questão importante na Teoria Crítica é a epistemologia. Como Geuss (1981, p. 1) argumenta:

A teoria da sociedade de Marx, se devidamente interpretada, claramente nos dá conhecimento da sociedade, mas não se enquadra facilmente em nenhuma das categorias de conhecimento aceitas. Obviamente, não é uma ciência formal como a lógica, a matemática ou uma habilidade prática... mas também não parece ser interpretada corretamente como uma teoria estritamente empírica como as das ciências naturais. Em vez disso, o marxismo é um tipo radicalmente novo de teoria; dar uma explicação filosófica adequada de suas características salientes requer revisões drásticas nas visões tradicionais sobre a natureza do conhecimento (Geuss, 1981, p. 1).

A Teoria Crítica visa "produzir esclarecimento... capacitando aqueles que a defendem determinar quais são seus verdadeiros interesses". Seu objetivo é a emancipação da coerção, incluindo a coerção autoimposta. Para este fim, é "reflexiva" (Geuss, 1981, p. 2).

A Teoria Crítica teve um impacto substancial no Direito (Unger, 1976); foi aplicada na História (Eagleton, 1985-1986; Lowenthal, 1985; Wallace, 1981, 1984), nas artes decorativas (St. George, 1985; Sweeney, 1984), na Literatura (Carravetta, 1984), na Geografia (Hay, 1979; Peet, 1975, 1977; Peet \& Lyons, 1981), e em estudos de museu (Baranik et al., 1977); e, é claro, tem feito parte da história e filosofia da ciência (Brannigan, 1981; Feyerabend, 1970; Latour \& Woolgar, 1979). Quase invariavelmente, uma das razões dadas para o emprego da Teoria Crítica é o fato de ela descrever e lidar com fatores - sociais, econômicos, políticos e psicológicos - que foram observados para influenciar as conclusões e seus usos sociais, mas que, sob muitas regras comuns da academia, não deviam estar presentes.

Os arqueólogos são convidados a considerar a Teoria Crítica, por um lado, porque as interpretações arqueológicas apresentadas ao público podem adquirir um significado não pretendido pelo arqueólogo e não serem encontradas nos dados. A análise de Leone (1981a, 1981b) sobre o uso da Arqueologia e da História na Colonial Williamsburg e em Shakertown é parte de um corpo de trabalho (Clarke, 1973; Gero et al., 1983; Handsman, 1981; Handsman \& Leone, s/d; Kehoe 1984; Landau, 1984; Lowenthal, 1985; Meltzer, 1981; Perper \& Schrire, 1977; Wylie, 1985a) que evidencia que, em contraste com a percepção geral dos arqueólogos americanos, em alguns ambientes nos Estados Unidos, a Arqueologia é usada para servir a objetivos políticos. Um incentivo adicional para explorar uma epistemologia reflexiva é a crescente controvérsia na Arqueologia sobre a propriedade e controle de vestígios e as interpretações do passado. O enterro de restos mortais e "repatriação" de alguns artefatos para grupos nativos pode ser uma questão tanto política quanto científica, da mesma forma como pode ser o uso da preservação, incluindo Arqueologia, para alterar o valor da propriedade em vilas e cidades em conexão com a mudança de localidades de diferentes grupos étnicos e de riqueza. Além disso, e menos visível e mais complexo, está o esforço dos arqueólogos em agências federais e estaduais nos Estados Unidos para controlar o uso e a preservação de vestígios arqueológicos em áreas cada vez maiores, 
incluindo terras privadas. Ostensivamente, um esforço neutro para proteger um recurso considerado, sem crítica, como valioso, inevitavelmente levanta preocupações sobre o monopólio do acesso aos dados e interpretações. É claro, então, que a prática da Arqueologia é afetada por decisões políticas, econômicas e sociais. A afirmação de uma Arqueologia crítica pressupõe a interrelação entre a Arqueologia e a política, permitindo aos arqueólogos a obtenção de conhecimento menos contingente.

Um conceito central para abordar a relação entre o conhecimento do passado e o contexto social e político de sua produção é a ideologia. A Teoria Crítica usa "ideologia" em muitos sentidos (ver Geuss, 1981). Nós usamos esse termo no sentido em que ele foi empregado por Althusser (1971a) e introduzido na antropologia por Barnett \& Silverman (1979). Sendo assim, a ideologia compreende os dados da vida cotidiana, aqueles despercebidos e vistos como certos, ativados e reproduzidos no uso. Ela é o meio pelo qual a desigualdade, a escravidão, a frustração etc. se tornam aceitáveis, racionalizadas ou ocultas. A ideologia serve para reproduzir a sociedade intacta; o conhecimento ou consciência da ideologia pode levar ao esclarecimento ou emancipação.

O conceito de ideologia foi empregado na Arqueologia por Tilley (1982), Miller (1982a, 1982b), Shanks \& Tilley (1982), Shennan (1982), Miller \& Tilley (1984), Shanks \& Tilley (s/d) e outros ao descrever a igualdade. A desigualdade implica a alienação do trabalho - o uso de bens ou serviços sem um retorno total do valor aos seus produtores. Uma palavra que pode descrever essa relação assimétrica é exploração. A ideologia oculta e mascara a exploração, ou a racionaliza, naturaliza ou supernaturaliza. Além disso, ela atua dentro de uma sociedade estratificada ou de classes para reproduzir a desigualdade sem resistência, violência ou revolução séria. Em vários sentidos, o termo "ideologia" foi aplicado à Idade do Bronze no noroeste da Europa por Shanks e Tilley (1982) e Thorpe (1981), aos Incas por Patterson (1984), ao oeste de Connecticut dos séculos XVIII e XIX por Handsman (1980, 1981, 1982), à civilização Harappan por Miller (1985), e às comunidades industriais dos séculos XIX e XX em Binghamton, Nova York, por McGuire (s/d). Todos esses exemplos se referem a sociedades estratificadas com mudanças nas relações de posse da riqueza. Em todos os casos, as análises resultantes ordenam os dados de uma maneira nova e levam em conta aspectos que às vezes foram esquecidos ou considerados intrigantes.

A ideologia pressupõe contradição, conflito potencial ou violência periódica na sociedade, e é parte de um conjunto de suposições que pode estar em forte conflito com os produtos acabados do funcionalismo, da teoria dos sistemas e de grande parte da teoria ecológica. A preocupação não é em relação ao bom funcionamento, em si, mas como o conflito e a contradição são mascarados ou naturalizados. A reconstrução da ideologia em sociedades pré-históricas, protoliteradas ou extintas é possível e é valiosa para abordar alguns dados arqueológicos até então inexplicados. Ela é relevante para a estratificação de classes, posse de riqueza e relações de poder e, em geral, seu estudo pode iluminar o que já se sabe das sociedades antigas. Argumentamos que esta é uma extensão da Teoria Crítica na Arqueologia.

A Teoria Crítica questiona sobre qualquer conjunto de conclusões a partir do ponto de vista no qual foram construídas. E esse questionamento visa ajudar a estabelecer o grau de validade da teoria. Exigir que estudos do passado forneçam conhecimento das circunstâncias atuais ou iluminem relações obscuras de hoje arriscaria a subordinação do passado, mas Lukacs (1971) fornece instruções úteis sobre como preencher a lacuna entre o conhecimento histórico, muitas vezes desencarnado, e a visão sobre a obrigação do historiador no quadro da Teoria Crítica. A seu ver, a tarefa do historiador é esclarecer as raízes da ideologia moderna, identificar as relações mistificadas entre classes e agentes, mostrar como essa mistificação é mantida por meio da ideologia e dar uma história às ideias usadas em sua manutenção. Essas ideias incluem, por exemplo, a de um passado 
objetivamente separado e a da pessoa como um indivíduo ou como possuidora de liberdade pessoal. Ideias como essas têm poder ativo. Uma vez que são vistas como ideológicas, as noções do passado, do indivíduo ou da liberdade pessoal não podem mais ser tomadas como dados atemporais. Esses dados podem receber uma história, contextualizar e mostrar que são politicamente ativos, e esse procedimento pode produzir esclarecimento. Sentimos que essa lógica pode ser trabalhada de forma convincente pela Arqueologia Histórica; mas, pela pré-história, por outro lado, é uma questão que ainda está em aberto.

Uma Arqueologia Crítica retém e reafirma o compromisso da disciplina com a compreensão do passado, mas o passado a ser construído torna-se uma questão de escolha consciente, que inevitavelmente envolve uma compreensão do contexto e do significado. Esses termos, agora tão usados na antropologia simbólica e por Hodder (1982, 1984, 1985), não significam a mesma coisa para todos. Para o teórico crítico, a ideologia tem muito a fornecer sobre o significado em uma sociedade, embora nem todo significado seja necessariamente ideologia. Por não ser epifenomenal, mero reflexo de outras realidades, mas central para a manutenção do status quo nas sociedades estratificadas, esse significado é considerado ativo ou recursivo, análogo à linguagem em suas qualidades formativas. Isso pode adicionar uma dimensão importante à definição de cultura material da Nova Arqueologia. A Teoria Crítica é materialista, mas nosso uso dela rejeita a ordem de classificação das relações causais de White, Harris e Vayda. Os filósofos que iniciaram a Teoria Crítica buscaram integrar a noção de consciência à epistemologia e, assim, criar um vínculo convincente e ativo entre a realidade material e uma consciência dela.

Nossa exploração de uma abordagem crítica ocorre no contexto de uma compreensão mais ampla do papel do positivismo na disciplina. O positivismo, uma abordagem que busca um conhecimento mais confiável do passado, enfatizando a relação entre as declarações científicas e seus testes, foi criticado por frequentemente produzir conhecimento tão estreito que parece irrelevante (ver, por exemplo, Hodder, 1984, 1985; Wylie, 1985b). Para Wylie, cuja orientação tendemos a seguir, o positivismo não deve ser abandonado, mas sim ajustado às realidades dos dados arqueológicos. Reconhecemos que o positivismo e a Teoria Crítica na Arqueologia ainda não foram sintetizados e não tentamos uma síntese aqui. Sugerimos que uma Arqueologia Crítica pode produzir um conhecimento mais confiável do passado, explorando os contextos sociais e políticos de sua produção.

A maneira como a Teoria Crítica pode ser aplicada à Arqueologia pode ser ilustrada por uma análise de dados dos séculos XVIII, XIX e XX de um projeto municipal conduzido em Annapolis, Maryland. Desde o seu início, o projeto denominado "Arqueologia em Annapolis" teve como objetivo desmistificar a Arqueologia, ensinar sobre como um passado é construído e descobrir como o passado foi usado localmente para compreender a ideologia local e identificar que aspectos dessa ideologia precisam ser esclarecidos.

\section{TEORIA CRÍTICA E ETNOGRAFIA DE ANNAPOLIS}

Quando "Arqueologia em Annapolis" começou em 1981 como uma colaboração entre a Universidade de Maryland e a Historic Annapolis, Inc. (uma organização privada de preservação voltada para a pesquisa estatal fundada em 1952), foi reconhecido que Annapolis não era apenas uma cidade antiga e bem preservada, mas também histórica. Como Annapolis se considerava histórica pelo menos desde a década de 1880, foi possível fazer uma análise antropológica de suas histórias, e esse esforço mostrou como fatores políticos estiveram 
embutidos na apresentação da cidade nos últimos 100 anos. Diante disso, presumimos que os achados arqueológicos não existiriam no vácuo, mas seriam assimilados pela compreensão da comunidade sobre seu próprio passado. Por esta razão, e devido à nossa abordagem crítica, o programa de pesquisa e o programa do museu associado ${ }^{6}$ tiveram que estar enraizados nos interesses e conflitos da comunidade. Consequentemente, o projeto teve um componente etnográfico desde o início.

A pesquisa etnográfica, conduzida por Potter, partiu do pressuposto de que, desde que se considerou histórica, Annapolis estruturou para si um passado que auxiliou e legitimou suas atividades contemporâneas. O primeiro passo de Potter foi um exame de uma ampla variedade de apresentações do passado em Annapolis 7 . Particular atenção foi dada às separações (Barnett \& Silverman, 1979) impostas ao passado que foram tratadas não como construções contemporâneas à composição de uma história, mas como categorias dadas ou quase naturais. Muitas dessas separações desempenham papéis estratégicos na sustentação do equilíbrio de poder em Annapolis hoje.

Annapolis é uma cidade pequena (cerca de 32.000 habitantes), mas complexa. Tem um governo municipal, é a sede do Condado de Anne Arundel e da Academia Naval dos Estados Unidos, uma instituição federal, e é a capital de Maryland. A economia da cidade gira em torno do governo estadual, da Academia Naval, do turismo e do iatismo, categorias que não são mutuamente exclusivas.

A cidade foi fundada por volta de 1650; mas a própria Maryland foi fundada em 1634. A capital de Maryland, St. Mary's City, localizada na parte sul da colônia, foi substituída por Annapolis em 1695, e a cidade foi fundada em 1708. Ela experimentou a chamada "Era de Ouro" de riqueza e fama desde meados de 1760 até o final da Revolução Americana. Durante esse período, Annapolis foi o centro social, político e econômico da Baía de Chesapeake. O fim da "Era de Ouro" coincidiu com dois eventos ocorridos na Casa do Estado de Maryland em Annapolis: (i) em 23 de dezembro de 1783, George Washington renunciou ao comando do Exército Continental (um movimento destinado a subordinar os militares à autoridade civil); e (ii), em 14 de janeiro de 1784, o Tratado de Paris com a Grã-Bretanha foi ratificado, encerrando oficialmente a Revolução Americana. Após a Revolução, Annapolis continuou sendo a capital, mas se tornou uma cidade-mercado regional, pois muitos de seus residentes mais ricos se mudaram para Baltimore e investiram na rápida expansão da cidade em um porto comercial e industrial internacional.

Em 1845, a Academia Naval dos Estados Unidos foi fundada em Annapolis mas, na maior parte do século XIX, a cidade estava no que um escritor chamou de "eclipse suave" (Norris, 1925). A década de 1950 viu o início de um renascimento comercial baseado em iates, turismo e novas rodovias que tornaram Annapolis um

\footnotetext{
6 "Arqueologia em Público", o programa de interpretação pública para "Arqueologia em Annapolis", consiste em quatro elementos, em quatro meios, que podem ser experimentados em qualquer ordem: (1) "Annapolis: Reflexões da Era da Razão," uma produção audiovisual sincronizada por computador de 20 minutos, com 12 projetores, (2) Annapolis Arqueológica: Um Guia para Ver e Entender Três Séculos de Mudança (Leone \& Potter, 1984), um guia de 24 páginas para uma parte do distrito histórico de Annapolis, (3) um passeio de 15 minutos por um sítio arqueológico em funcionamento, oferecido por um arqueólogo, e (4) três pequenas exposições arqueológicas localizadas em edifícios de museus ao redor do distrito. A apresentação audiovisual trata de maneiras de compreender a crescente segmentação e padronização da cultura material na Annapolis do século 18, visto que estão relacionadas à obtenção de lucro. O guia leva o leitor a oito pontos, e em cada um mostra como as interpretações históricas em Annapolis mudaram - e continuam a mudar - com as transformações nas preocupações políticas. A visita ao local, discutida em detalhes abaixo (e ver Leone, 1983; Potter \& Leone 1986, s/d), concentra-se na lógica ou método arqueológico e nas conexões entre os objetivos do trabalho arqueológico e as questões políticas em Annapolis hoje. As exibições de artefatos (ver $n^{\circ} 13$ ) mostram nossa compreensão da cultura material como recursiva.

${ }^{7}$ O banco de dados etnográfico de Potter inclui quatro histórias do tamanho de um livro de Annapolis, vinte guias históricos e livros ilustrados, meia dúzia de grandes reconstituições históricas e passeios especiais, duas dezenas de palestras históricas, passeios e eventos menores, meia dúzia de entrevistas formais, produtos de observação participante no Distrito Histórico do centro por mais de três anos, e várias centenas de horas de interação informal, mas intensa e engajada na comunidade, de preservação histórica local.
} 
subúrbio atraente para Washington, D.C., a menos de 30 milhas $^{8}$ de distância. A preservação histórica desempenhou um papel importante no renascimento comercial de Annapolis. É esse esboço básico, ou parte dele, que é transmitido ao público por guias turísticos, livros turísticos e museus históricos como a história de Annapolis.

A pista inicial de Potter foi a sensação de que a história de Annapolis, conforme apresentada aos turistas na cidade, era composta por uma série de fragmentos. A história é contada por uma ampla gama de grupos e instituições, alguns sobrepostos, alguns em competição, alguns em cooperação. E o mais importante: não há nenhuma história de Annapolis que demonstra como todas as diferentes partes da cidade se encaixam. Desse modo, a cidade é apresentada como um conjunto de unidades não conectadas (períodos de tempo e instituições). Também desconectadas estão as populações negra e branca, de um lado, e a cidade e a Academia Naval dos Estados Unidos, do outro.

Em Annapolis, a história negra é apresentada separadamente da história branca. Ao segregar as raças temporalmente (a história dos brancos é a história do século XVIII, e a história dos negros é a história do século XIX), a história de Annapolis, escrita quase exclusivamente por brancos, impõe um quadro de referência que ignora a principal relação histórica entre negros e brancos em Maryland e o resto do sul dos Estados Unidos: escravidão. Isso, por sua vez, torna difícil para a escravidão ser vista como um antecedente das relações entre os grupos hoje. Também evita que os negros usem a escravidão como referência na comparação de seu presente com seu passado.

O mesmo tipo de lógica funciona com a relação entre a cidade e a Academia Naval dos Estados Unidos. Há uma ampla base para apresentar a cidade e a academia como historicamente conectadas ou historicamente separadas. A escolha dos historiadores da cidade se torna clara pelo título de uma história influente: Annapolis: Its Colonial and Naval Story (Norris, 1925). A mistura de categorias no título é instrutiva. O subtítulo de Norris poderia ser Sua história dos séculos XVIII e XIX ou A história da cidade e a Academia Naval. Ao misturar termos temporais e institucionais, ele reforça a identidade entre cidade e século XVIII, academia e século XIX. A análise detalhada mostra uma apresentação consistente da cidade como "do século XVIIP" (ou, como dizem seus residentes, "antiga"), isto é, de tijolos, pequena, lenta, evocativa e associada a residentes brancos; e da academia como "dos séculos XIX e XX", ou seja, de granito, rápida, científica e associada aos transeuntes brancos, que são seus alunos, e aos residentes negros, que são seus empregados. Contra essas separações estão as extensas conexões históricas e contemporâneas entre a cidade e a academia, entre elas: a dependência econômica da cidade à academia e as numerosas expansões da academia na cidade.

As separações representadas como interpretações históricas precisas do passado são apresentadas aos residentes e visitantes como dados sobre o passado, mas ocultam conflitos politicamente vivos entre instituições e grupos na cidade contemporânea. Nossa hipótese é de que esses conflitos, caso sejam descobertos nas apresentações históricas e usados como base para a ação, representariam ameaças para as forças políticas concorrentes: prefeitura, Academia Naval, preservacionistas e minorias. Essas forças e as separações que ocultam seus relacionamentos reais são importantes e significativas para a Annapolis contemporânea.

Para resumir, as principais separações em Annapolis são: século XVIII/século XIX, brancos/negros, Distrito Histórico/Academia Naval, residentes/visitantes. Uma separação abrangente que unifica o restante é

\footnotetext{
${ }^{8} \mathrm{~N}$. de T.: 48 quilômetros.
} 
interno/externo ${ }^{9}$. Essa separação também é baseada na história. E a história da relação da cidade com o mundo exterior é de subserviência autoimposta. Annapolis trabalhou muito para se tornar a capital de Maryland (Riley, 1976 [1887], p. 57). Ela tentou, e não conseguiu se tornar a capital permanente dos Estados Unidos logo após a Revolução (Riley, 1976 [1887], p. 198-200). A Academia Naval foi fundada depois que a cidade manteve um namoro de 20 anos para obtê-la (Riley, 1976 [1887], p. 264). No final do século XIX foi elaborada uma campanha malsucedida para atrair negócios e indústria para Annapolis (Riley, 1976 [1887], p. 323-24; 1897, 1901, 1906). Finalmente, na década de 1980 a cidade trabalhou para se promover como um centro turístico e de iates, papel desempenhado pelo movimento de preservação histórica. Em cada um desses casos, Annapolis convidou pessoas de fora para entrar e lucrou ao fazê-lo ao mesmo tempo que se apresentava como um recurso estável e historicamente significativo, não especialmente dependente de pessoas de fora.

Enquanto a análise das separações brancos/negros e cidade/academia é baseada principalmente em como a história é apresentada em Annapolis, a análise da separação residente/visitante depende mais do que é apresentado. Muito se falou sobre as vinte visitas de George Washington (Baldridge, 1928; Historic Annapolis, lnc. s.d.; Norris, 1925, p. 191-224; Riley, 1976 [1887], p. 200-207, 218-20; Thomas, 1952), e sobre as apresentações de suas conexões com a cidade, Washington, o Pai de Seu País, é ofuscado por Washington, o criador de cavalos, patrono das artes e festeiro, em suma, Washington, o turista. O palpite de Potter é que, com o exemplo de Washington, os visitantes aprendem como Annapolis deseja que eles se comportem durante sua estada na cidade. Devem ser ricos, elegantes, atenciosos e sociáveis, e devem voltar para casa deixando apenas o suficiente de sua "aura" para atrair outros como eles. Washington é um modelo do forasteiro perfeito.

A etnografia resumida serve como um guia para o que um programa arqueológico baseado na Teoria Crítica deve ensinar às 5.000-10.000 pessoas por ano que visitam os sítios arqueológicos abertos em Annapolis. Desde 1982, "Arqueologia em Annapolis" abordou duas das separações identificadas por meio de escavações arqueológicas abertas ao público.

Na primavera de 1985, os arqueólogos realizaram uma excursão pelo sítio Pousada State House ${ }^{10}$. O objetivo da escavação era reunir informações detalhadas sobre o padrão de rua de 290 anos da cidade, chamado de plano de Nicholson, e sobre o histórico de suas mudanças. Os participantes do passeio foram informados, para começar, que há duas maneiras de olhar para o plano barroco das ruas da cidade de dois círculos e ruas radiantes traçado pelo governador Francis Nicholson em 1695: como uma obra de arte, uma relíquia inalterada dos anos 1600, ou como continuamente alterado e ajustado para atender às necessidades das pessoas que moravam e trabalhavam em Annapolis ao longo dos séculos. O motivo para escavar na Pousada State House, foi explicado, eram as comparações entre o mapa mais antigo conhecido de Annapolis (o levantamento Stoddert de 1718) e mapas modernos, os quais mostravam que o Círculo Estadual, no qual a pousada estava situada,

\footnotetext{
${ }^{9}$ A classificação das pessoas associadas à academia como "visitantes" é óbvia; alguns professores, a maioria dos administradores e todos os alunos passam pela academia em missões que duram cerca de quatro anos. Além disso, na descrição da Annapolis contemporânea que começa sua influente história da cidade, Stevens (1937) diz que a melhor época para visitar Annapolis é durante a Semana de Comissionamento da Academia Naval, a formatura da academia, porque então a cidade velha ganha vida. Ele diz que fica melhor quando está lotada com as famílias e namoradas de aspirantes a se formar. A transformação de residentes negros em "visitantes" é menos óbvia, mas Stevens aponta o caminho. No curso de apenas cerca de trinta páginas, ele se refere a um bairro negro como "Etiópia" e a um motorista de táxi negro como "um senegambiano antigo". O efeito, senão a intenção, de ligar os negros aos países africanos é torná-los "visitantes" ou, pelo menos, não residentes originais de Annapolis. Ao transformar grupos associados à academia e aos negros em "visitantes", aqueles que escreveram e usaram a história da cidade tentaram se definir como "residentes", fortalecendo assim sua reivindicação de poder político local.

${ }^{10}$ As escavações no sítio State House Inn foram supervisionadas por Joseph W. Hopkins, III (University of Maryland, College Park), assistido por Donald K. Creveling (University of Maryland, College Park) e Paul A. Shackel. A visita ao local foi conduzida por Pamela Henderson e Kristen Peters para mais de 4.300 visitantes entre 22 de abril e $1^{\circ}$ de junho de 1985.
} 
havia sido reduzido em 30-60 pés ${ }^{11}$, sem qualquer registro das mudanças. A evidência arqueológica para o encolhimento do Círculo Estadual foi então apontada: dois cortes no subsolo natural que podem representar bordas de diâmetros de círculo anteriores maiores, e uma fileira de postes perto de um dos cortes que pode ter sido a linha de uma cerca servindo como uma fronteira entre um Círculo Estadual maior e um pátio (Hopkins, 1986). Foi sugerido ainda que os dados do sítio Pousada State House seriam combinados com informações de outros sítios ao redor do círculo, como o sítio Calvert House (Yentsch, 1983), para produzir uma imagem mais completa e cumulativa de todas as pequenas alterações que adicionaram até uma diferença total entre o Círculo Estadual do século XVIII e o Círculo Estadual de hoje. De pequenas alterações à planta de Nicholson, a apresentação passou a descrever a maior alteração no padrão das ruas do século XVIII, que foi feita pela Academia Naval dos Estados Unidos em 1906 quando esta se separou do resto da cidade e criou seu próprio plano de ruas. Com essa alteração, observou-se que as estradas e plantas urbanas contêm informações destinadas a direcionar o comportamento e o pensamento das pessoas que os utilizam. A substituição, pela academia, dos elementos da cidade do século XVIII por um plano próprio foi parte de uma tentativa maior de fazê-la parecer separada do resto da cidade, embora, na verdade, houvesse muitas conexões poderosas entre as duas. A excursão mostrou como as ruas de Annapolis podem ser vistas como uma ideologia, mascarando uma realidade significativa e potente.

Para iluminar a separação entre residentes e visitantes e, ao mesmo tempo, para processar dados arqueológicos de uma forma que revelassem os detalhes da vida do século XVIII; materiais do sítio Victualling Warehouse, do sítio Hammond-Harwood House e do sítio Thomas Hyde House (193 Main Street) foram analisados $^{12}$ e incorporados na apresentação ao final, uma obra do século XVIII e local doméstico. Nossa hipótese é de que a variação crescente encontrada nos conjuntos de cerâmica nos locais do século XVIII e início do século XIX em Annapolis é um reflexo da crescente participação na cultura associada ao capitalismo mercantil. Uma cidade colonial caracterizada pela importação, exportação, mercadores, plantadores, manufatura e consumo de uma ampla gama de bens produzidos em massa deve ser caracterizada pela crescente segmentação e padronização de muitos aspectos da atividade diária (Braudel, 1979a, p. 207; Braudel, 1979b, p. 377- 78; Deetz, 1977, 1983; Detweiler, 1982, p. 24-25; Smith, 1937 [1776], p. 3-13). Postulamos que o crescimento do capitalismo mercantil que conhecemos caracterizou Annapolis no século XVIII (Carr \& Walsh, 1986; Papenfuse, 1975, Middleton, 1953) e está associado à padronização dos domínios da vida, por um lado, e à crescente intercambialidade das coisas, atos e pessoas, por outro. Argumentamos que a segmentação e padronização no uso de cerâmica em Annapolis acompanham uma etiqueta associada ao acúmulo de lucro. Tanto esta quanto aquela serão refletidas na cultura material usada em muitos aspectos da vida diária, incluindo a mesa e seu cenário, à medida que as pessoas forem incorporadas à vida do capitalismo (Braudel, 1979a, p. 203-9). Deetz (1977) e Carr e Walsh (s.d.; Walsh, 1983) argumentaram que durante o século XVII as pessoas na Anglo-América viviam um modo de vida menos diferenciado, caracterizado pela solidariedade mecânica no

\footnotetext{
${ }^{11}$ N. de T. 9-18 metros.

${ }^{12}$ O local do Victualling Warehouse foi escavado sob a direção de Constance A. Crosby (University of Califórnia, Berkeley) durante os verões de 1982 e 1983. As escavações no local da Harnmond-Harwood House foram supervisionadas por Richard J. Dent (University of Maryland, College Park) durante a primavera de 1983 e a primavera de 1984, auxiliado na segunda temporada por Robert C. Sonderrnan. As escavações do local da Thomas Hyde House no inverno de 1985-86 e no verão de 1986 foram dirigidas por Paul A. Shackel, assistido por Dorothy Humpf (Pennsylvania State University) e Lynn Clark (State University of New York em Binghamton) durante o verão de 1986. A medição dos fragmentos de cerâmica em que a análise foi baseada foi feita por Raymond Tubby, Diana Kehne e Theresa Churchill (University of Maryland, College Park).
} 
sentido de Durkheim. Comer, dormir e outras atividades tendiam a ocorrer em um único cômodo. Os membros de uma família comiam sentados em camas, baús ou bancos puxados para uma mesa. Uma travessa ou uma caneca eram usadas por várias pessoas. Garfos de mesa, especiarias e cerâmicas importadas eram itens de luxo, vistos apenas em famílias mais ricas. No século XVIII, as partes da vida cotidiana tornaram-se mais diferenciadas umas das outras, com a performance sendo definida por lugar, regras, ferramentas e público. Novas regras de comportamento, que separavam as pessoas, se desenvolveram e foram escritas (Braudel, 1979a; Deetz, 1977, 1983; Glassie, 1975). Braudel (1979a , p. 203-209) cita Les delices dela campagne (Os prazeres do campo) de Nicholas de Bonnefons, publicado em 1654, como um exemplo. Nessa obra, recomenda-se que os lugares à mesa sejam espaçados a uma distância da largura de uma cadeira e especifica-se o número de pratos a serem servidos, a troca de pratos ao final de cada serviço e a troca de guardanapos a cada dois serviços. Essa tendência é observada em inventários de Annapolis do século XVIII (Shackel, 1986a). Itens de jantar definidos por regras que segmentavam a mesa de jantar em muitas partes (pratos de salada, terrinas, tampas de pratos, aquecedores de pratos, pudim e copos de creme, garrafas ou galhetas para servir condimentos, barcos de manteiga e taças de vinho) ${ }^{13}$ ocorreram exclusivamente entre os ricos até o terceiro quarto do século XVIII. Nesse ponto, os padrões de consumo mudaram drasticamente (Carr \& Walsh, 1977, p. 32-33; Walsh, 1983, p. 111), e muitos itens de segmentação começaram a ser usados em todos os níveis de riqueza, exceto para os mais baixos ${ }^{14}$.

A segmentação de tarefas, a padronização de produtos por meio da produção em massa e a padronização do comportamento produtivo por meio de regras passaram a permear a vida cotidiana em Annapolis no decorrer do século XVIII. Arqueologicamente, sabemos que o trabalho foi primeiro separado das atividades domésticas no espaço doméstico, depois transferido para um edifício ou área diferente e, por fim, transferido para uma parte totalmente diferente de Annapolis, o que ocorreu no início do século XIX. Braudel (1979b, p. 377-378) sugere que tal segmentação acompanha uma ordem com fins lucrativos. Argumentamos que a maior variedade de tamanhos e tipos de pratos, que mede a segmentação das pessoas durante a alimentação e a segmentação dos alimentos em serviços e por tipo, é também uma medida do processo mais amplo em funcionamento na sociedade mercantil.

Os três locais que examinamos variaram em características socioeconômicas. O sítio Victualling Warehouse era uma estrutura residencial e comercial de um grupo de renda média; já o sítio da HammondHarwood House era uma casa de um grupo de elevado poder aquisitivo; e o sítio da Thomas Hyde House era uma casa e negócio de um comerciante que escalou do grupo de menor riqueza na década de 1740 para o grupo de maior riqueza no terceiro quarto do século XVIII ${ }^{15}$. Para determinar se uma nova ordem de comportamento

\footnotetext{
${ }^{13}$ Este inventário de elementos de uma refeição foi compilado por Lorena Walsh, da Colonial Williamsburg Foundation. Seu uso na análise de Shackel foi sugerido por Lois Green Carr da St. Mary's City Commission.

${ }^{14}$ Essas mudanças nos padrões foram produtos de transporte, propaganda e tecnologia aprimorados (Carr \& Walsh, 1977; Walsh, 1983, p. 113), bem como um novo tipo de trabalho rotinizado.

${ }^{15} \mathrm{O}$ sítio do Victualling Warehouse fica dentro do distrito comercial de Annapolis, próximo ao porto. De meados do século 18 até 1790 , o local continha duas estruturas usadas para fins comerciais e residenciais. Ambas as estruturas foram queimadas em 21 de janeiro de 1790. Uma foi reconstruída logo em seguida, enquanto a outra foi demolida quase ao mesmo tempo (Crosby, 1982, p. 1-3). O incêndio forneceu um controle cronológico firme para nossa análise.

A Hammond-Harwood House é uma mansão georgiana de cinco partes projetada e construída por William Buckland, entre 1774 e 1775 para Mathias Hammond. Esse local foi escavado em camadas estratigráficas (Dent, 1985) que forneceram a base para o controle cronológico. A Thomas Hyde House era uma estrutura de tijolos em estilo georgiano construída na década de 1760 no coração do centro social e político da cidade. O local continha vários edifícios anexos, incluindo uma cozinha de verão, uma casa de leite e latrinas. A casa foi construída sobre uma estrutura anterior do primeiro quarto do século 18. Esse local também foi escavado em camadas estratigráficas (Shackel, 1986b), permitindo o controle cronológico e facilitando a comparação com outros sítios.
} 
era visível arqueologicamente, examinamos a variedade de tipos de cerâmica recuperadas e diâmetros de pratos ao longo do tempo ${ }^{16}$. A fórmula a seguir foi desenvolvida para quantificar a variação em cada conjunto de cerâmica:

$($ tamanhos-tipos/tipos) $\mathrm{x}($ tamanhos $)=$ valor índice

"Tipos" se refere ao número de tipos de cerâmica padrão (por exemplo, porcelana, pearlware, creamware; "tamanhos", ao número de diâmetros de pratos diferentes (arredondado para a meia polegada mais próxima); e "tamanhos-tipo", ao número de tipos e combinações de tamanho representados.

Portanto, na montagem hipotética da Tabela 1, em um conjunto que contém um prato de porcelana de 7 polegadas e um de 9 polegadas; um prato de whiteware de 4 polegadas e um de 9 polegadas; e um prato de porcelana de 8 polegadas; existem três tipos, quatro tamanhos e cinco tamanhos-tipo de acordo com nossa fórmula: $(5 / 3)(4)=20 / 3$ ou 6,67 como medida de variação.

Valores deste tipo, isto é, de locais diferentes ou estratos diferentes no mesmo local, podem ser comparados para medir mudanças ao longo do tempo e diferenças entre grupos de riqueza. Um valor próximo a 1,0 indica variação baixa, valores maiores aumentam a variação. Os dados dos três locais foram divididos em início do século XVIII, meados ao final do século XVIII, final do XVIII ao início do século XIX, e meados do século XIX. Os índices de variação calculados para cada conjunto sugerem que os residentes de todos os três locais estavam participando cada vez mais de um modo de vida padronizado e segmentado (Tabela 2). A maior variedade de tamanhos de pratos e utensílios no registro arqueológico reflete uma nova etiqueta, uma segmentação crescente à mesa, que serviu tanto como campo de treinamento para a nova ordem quanto para seu reforço.

Tabela 1. Variação em um Conjunto Hipotético de Cerâmica.

\begin{tabular}{c|c|c|c|c|c|c}
\cline { 2 - 6 } & $\begin{array}{c}\text { Diâmetro } \\
\text { do Prato } \\
\text { (polegadas) }\end{array}$ & $\begin{array}{c}\text { Diâmetro } \\
\text { do Prato } \\
\text { (polegadas) }\end{array}$ & $\begin{array}{c}\text { Diâmetro } \\
\text { do Prato } \\
\text { (polegadas) }\end{array}$ & $\begin{array}{c}\text { Diâmetro } \\
\text { do Prato } \\
\text { (polegadas) }\end{array}$ & $\begin{array}{c}\text { Diâmetro } \\
\text { do Prato } \\
\text { (polegadas) }\end{array}$ & $\begin{array}{c}\text { Diâmetro } \\
\text { do Prato } \\
\text { (polegadas) }\end{array}$ \\
\hline $\begin{array}{c}\text { Tipo de } \\
\text { Cerâmica }\end{array}$ & 4 & 5 & 6 & 7 & 8 & 9 \\
\hline Porcelana & - & - & - & - & $\mathrm{X}$ & - \\
\hline Pearlware & - & - & - & $\mathrm{X}$ & - & $\mathrm{X}$ \\
\hline Whiteware & $\mathrm{X}$ & - & - & - & - & $\mathrm{X}$ \\
\hline
\end{tabular}

\footnotetext{
${ }^{16}$ Nossa análise é experimental e preliminar. Como as contagens mínimas de vasos ainda não foram clonadas para esses sítios, os dados são
} apenas em termos de fragmentos. Ezra Zubrow (State University of New York em Buffalo) ajudou a escrever a fórmula que mede a variação. 
Tabela 2. Variação em Conjuntos de Cerâmica de Três Sítios de Annapolis, Início do século 18 a Meados do século 19.

\begin{tabular}{c|c|c|c|c}
\hline \multirow{2}{*}{ Sítio } & Período & Período & Período & Período \\
\cline { 2 - 5 } & Início do $\mathbf{1 8}$ & $\begin{array}{c}\text { Meados ao fim } \\
\text { do } \mathbf{1 8}\end{array}$ & $\begin{array}{c}\text { Fim do 18 ao } \\
\text { Início do 19 }\end{array}$ & Meados do 19 \\
\hline $\begin{array}{c}\text { Victualling } \\
\text { Warehouse }\end{array}$ & n.d. & $3.6(\mathrm{n}=572)$ & $12.0(\mathrm{n}=1.698)$ & n.d. \\
\hline $\begin{array}{c}\text { Hammond- } \\
\text { Harwood House }\end{array}$ & n.d. & $2.0(\mathrm{n}=122)$ & $27.0(\mathrm{n}=926)$ & n.d. \\
\hline $\begin{array}{c}\text { Thomas Hyde } \\
\text { House }\end{array}$ & $1.0(\mathrm{n}=22)$ & $2.0(\mathrm{n}=37)$ & $24.5(\mathrm{n}=76)$ & $73-1(\mathrm{n}=368)$ \\
\hline
\end{tabular}

\section{UM PASSEIO PELO SÍTIO ARQUEOLÓGICO BASEADO NA TEORIA CRÍTICA}

Os visitantes de Annapolis interagem diretamente com arqueólogos envolvidos na escavação de materiais relacionados ao passado. Nem todos os locais escavados em Annapolis (cerca de 20 desde 1981) estão abertos aos visitantes, mas aqueles localizados no coração da área turística (6 desde 1982) são utilizados para esse fim. As visitas a alguns locais são fornecidas sob demanda, de até 40 por dia, em dias e locais movimentados, e o número médio de visitantes por turno é por volta de cinco. Os passeios têm como objetivo ensinar aos participantes como questionar e desafiar seus guias e outras pessoas que criam, interpretam e apresentam o passado. Cada sítio aberto tem sua própria apresentação. Em consulta com um especialista em mídia ${ }^{17}$, a seguinte estrutura básica foi desenvolvida: (1) boas-vindas, (2) introdução do guia arqueólogo, (3) introdução da equipe arqueológica, (4) introdução do projeto, incluindo fontes de financiamento, (5) introdução do local específico, (6) discussão de técnicas arqueológicas, (7) conteúdo ou argumento antropológico, (8) conclusão e (9) período de perguntas (ver Leone, 1983; Potter \& Leone, 1986, s.d.).

Durante o verão de 1986, as escavações foram realizadas em um estacionamento na Main Street ${ }^{18}$, que até os anos 1930 continha a casa de dois andares e meio de Thomas Hyde. A discussão no sítio era a seguinte:

Agora que falei sobre quem somos e como escavamos, gostaria de contar por que estamos escavando aqui.

Como mencionei há alguns minutos, uma classe importante de achados arqueológicos é a cerâmica. A maior parte dos utensílios de cerâmica usados neste país, durante a primeira metade do século XIX, foi feita na Inglaterra, e como sabemos quando esses itens foram feitos, podemos usar seus fragmentos para nos ajudar a datar sítios arqueológicos.

Mas as cerâmicas são úteis para além da datação. Em meados do século XVIII, houve uma revolução na fabricação e comercialização da cerâmica de barro inglesa liderada por Josiah Wedgwood. Wedgwood e outros desenvolveram materiais e técnicas que permitiram a fabricação em massa de utensílios de mesa, relativamente baratos, em conjuntos combinados. Antes de meados de 1700, os itens de cerâmica geralmente não vinham em conjuntos e eram geralmente usados em comunidade, várias pessoas comendo em um recipiente e compartilhando outros para beber. A revolução de Wedgwood mudou tudo isso. Wedgwood introduziu pratos que permitiam a cada comensal ter seu próprio prato idêntico aos dos outros comensais. Ele também criou conjuntos de pratos que incluíam diversos tamanhos e formatos de recipientes para diferentes pratos. Um conjunto adequado de pratos tinha pratos de sopa e pratos de café da manhã e pratos de sobremesa e pratos de manteiga, além de pratos regulares. E assim por diante.

\footnotetext{
${ }^{17}$ O consultor de mídia é Philip Arnoult, diretor do Theatre Project em Baltimore.

18 O programa público na Thomas Hyde House foi dirigido por Patrícia A. Secreto (University of Maryland, College Park) e Christine Hoepfner (University of Pennsylvania). Junto com Samuel T. Brainerd, Lynn Clark, Teri Harris, Bill Helton e Anne A. Tschirgi, eles conduziram a excursão que ocorreu entre 10 de julho a 16 de agosto, apresentando o programa a mais de 3.800 visitantes.
} 
Sentimos que o uso de um conjunto de pratos totalmente elaborado, como agora, não era simplesmente uma questão de costumes, desligada do resto da vida. Na elaboração de tamanhos e formas de pratos há um processo duplo de segmentação e padronização. Pratos separados segmentam os comensais em uma mesa junto com as regras de etiqueta - usando o "garfo certo", e assim por diante. Boas maneiras e pratos forneciam regras e divisões claras que diziam e mostravam aos indivíduos como se relacionar uns com os outros. A refeição foi segmentada aqui por volta de 1750, e as regras de alimentação segmentaram a sociedade, separando as pessoas.

Enquanto isso, o processo de trabalho segmentado e produção em massa, que padronizou os pratos, padronizou também muitos outros tipos de produtos manufaturados. Os pratos, cujos cacos estamos desenterrando aqui, serviam para regularizar o comportamento alimentar de quem os utilizava e, ao mesmo tempo, a regularidade era produto de um processo de fabricação e de uma vida controlada para os trabalhadores que os fabricavam. Muito da cultura material estava sendo padronizada e muito do comportamento humano também. Essas ideias merecem nossa atenção porque, embora fossem novas em meados de 1700, muitas delas ainda estão entre nós hoje e são tidas como certas, como supomos que o mundo sempre funcionou. E se tomarmos essas coisas como verdadeiras, perdemos a oportunidade de entender seu impacto sobre nós ou de mudá-los. É assim que pensamos sobre as cerâmicas que desenterramos.

Essas ideias sobre segmentação não têm a ver apenas com pratos. Assim como os pratos individuais e as travessas especializadas separavam os alimentos dos comensais, as casas passaram a ter cada vez mais cômodos, com atividades diferentes sendo realizadas separadamente, em cômodos separados. Antes de 1700, muitas atividades relacionadas ao trabalho e tarefas domésticas ocorriam na mesma sala de casa. Em 1750, as pessoas estavam construindo casas com quartos separados para comer, dormir, cozinhar e trabalhar. E as pessoas mais ricas, como as das Casas Paca e Brice, levaram isso ainda mais longe, com música, cartas e salões de baile. Pratos e alimentação foram segmentados; as casas e a vida doméstica foram segmentadas: vida profissional, vida social e vida familiar. No início do século XVIII, o trabalho e as atividades domésticas geralmente aconteciam no mesmo lugar. Em 1800, em Annapolis, as pessoas dividiam o trabalho da vida doméstica, preferindo lojas, tavernas e escritórios em prédios separados de suas casas. Casas como esta que estamos escavando eram usadas apenas para a vida doméstica em 1800. Na época em que a fabricação em grande escala começou em Baltimore, em 1850, o trabalho estava localizado longe de casa e a distância ficou cada vez maior.

Achamos que as pessoas aprenderam a dividir suas vidas e aceitar as divisões e os papéis para a divisão em casa, na mesa, e em todas as outras tarefas que também estavam se separando.

Até agora, falei sobre várias separações diferentes que começaram a entrar na vida americana no século XVIII. Gostaria de passar para uma separação final, aquela entre o tempo de trabalho e o tempo de lazer. Essa segmentação de tempo cria a possibilidade de algo com que muitos de vocês possam estar envolvidos agora, férias. Tenham em mente, nos próximos minutos que essa invenção cultural em particular, a ideia de férias, só entrou na vida americana há cerca de cem anos, depois que Thomas Hyde construiu sua casa neste local.

Férias e turismo são uma grande indústria e um grande problema em Annapolis, como em muitas outras pequenas cidades históricas. Todos os anos, mais de 1.000 .000 pessoas visitam Annapolis, uma cidade de apenas 32.000 habitantes, então é fácil entender o interesse da cidade em prestar atenção especial ao turismo aqui; a cidade trabalha muito para proteger as coisas que atraem os visitantes. Como eu disse, a necessidade de controlar um grande fluxo de visitantes não é exclusiva de Annapolis. O que é único, é uma parte da solução de Annapolis para esse problema potencial.

De maneiras muito sutis, Annapolis tenta usar George Washington para guiar o comportamento do visitante. Desde que a cidade se considerou histórica, os guias e histórias locais incluíram muitas referências a George Washington e suas vinte ou mais visitas à cidade. Em muitos desses relatos, há uma forte ênfase nos aspectos sociais e domésticos das visitas de Washington à cidade: suas idas à pista de corridas, os bailes a que compareceu, as peças de teatro a que assistiu, e os familiares e amigos que visitou. A imagem de Washington que surge é muito semelhante ao perfil do tipo de visitante que Annapolis disse publicamente que deseja atrair: o "turista de qualidade". Conforme definido durante uma campanha eleitoral local e, desde então, nos jornais locais, um "turista de qualidade" é aquele que gasta algum dinheiro na cidade sem atrapalhar ninguém, nada ou deixar uma bagunça para trás. O efeito das apresentações de Washington, que o fazem parecer o tipo de visitante que Annapolis tenta atrair hoje, é o que tornou Washington um turista modelo ou um modelo de comportamento turístico desejável. O que torna esse retrato sutil e inconsciente de Washington como um turista modelo tão interessante, é que o turismo e as férias só foram inventados 80 anos ou mais após a sua morte. George 


\begin{abstract}
Washington nunca poderia ter sido um turista porque, o turismo como o conhecemos, além do Grand Tour, não existiu durante sua vida.

Nos últimos 15 minutos, tentei fazer duas coisas. Ao discutir as origens de alguns aspectos tidos como certos da vida contemporânea, separações e segmentação, tentei mostrar que nosso modo de vida não é inevitável; tem suas origens e suas razões, e está aberto a questionamentos e desafios como resultado. A segunda coisa que tentei fazer, por meio do exemplo de George Washington, é mostrar maneiras pelas quais a história é frequentemente feita e apresentada para propósitos contemporâneos. Na próxima vez que você vir uma apresentação da história, visitar um museu, fazer uma excursão, assistir a um programa de televisão sobre o passado, ou o que quer que seja, você pode se perguntar o que essa versão da história está tentando fazer com que você faça ${ }^{19}$.
\end{abstract}

Este é o tipo de apresentação feita em cada um dos seis sítios arqueológicos abertos em Annapolis ${ }^{20}$. Cada apresentação termina com uma declaração sobre a relevância do passado para o presente, abordando uma das separações, como interno/externo, que foi descoberta pela etnografia dos usos do passado em Annapolis. Cada apresentação também inclui uma declaração de nossa esperança de que a excursão tenha ajudado as pessoas a se tornarem mais críticas em relação às apresentações do passado. Isso preenche um requisito de uma Arqueologia Crítica: elementos esclarecedores da vida diária que normalmente estão ocultos. Mas, se o esclarecimento deve levar à ação social a lidar com a contradição mascarada pela ideologia, é uma questão em aberto.

A etapa final para tornar o projeto como uma pesquisa de Arqueologia Crítica é a avaliação do impacto dos passeios sobre os participantes. Existem muitas medidas informais, principalmente adaptadas de procedimentos de avaliação de museus, sobre o grau de compreensão das mensagens. Uma delas é o número de perguntas feitas pelos visitantes ao final de um passeio. Registramos as perguntas e comentários dos visitantes, tratando assim o sítio arqueológico aberto como um contexto etnográfico. Não é incomum que os visitantes voltem aos sítios uma segunda, terceira ou quarta vez, demonstrando uma compreensão dos sítios como ambientes educacionais em constante mudança. Os visitantes, às vezes, voltam ao local com amigos, como guias; nesses casos, pode-se dizer que esses visitantes, certamente, foram emancipados.

Desde 1982 um questionário de avaliação de uma página é distribuído aos visitantes ao final de uma excursão. Os entrevistados são auto selecionados e a amostra é de cerca de 10\% dos visitantes, uma grande amostra em comparação com as usadas na maioria das avaliações de museus (Zannieri, 1980, p. 7). Além das perguntas que os visitantes responderam simplesmente selecionando as respostas em uma lista, fizemos perguntas que exigem respostas curtas por escrito. Uma dessas perguntas, utilizada em nosso formulário de avaliação no sítio Shiplap House ${ }^{21}$, que gerou muitas respostas informativas, foi: "O que você aprendeu sobre

\footnotetext{
${ }^{19}$ Além da excursão na Thomas Hyde House, os visitantes em 1986 foram convidados a visitar três exposições arqueológicas, para as quais foram encaminhados por um panfleto. Escovas de dente arqueologicamente recuperadas estavam em exibição no histórico Annapolis, Inc., escritório turístico em uma exposição projetada e escrita por Paul A. Shackel. A exposição pretendia demonstrar a crescente padronização da fabricação de escovas de dente durante o século 19 e, ao mesmo tempo, explicar que o uso crescente de escovas de dente e outros itens de higiene pessoal sinalizava uma crescente autorregulação e adesão às regras de comportamento por parte dos moradores de Annapolis. (Além das escovas de dente escavadas em Annapolis, essa exposição continha três escovas de dente emprestadas do Baltimore Center for Urban Archaeology). Uma segunda exposição, projetada e escrita por Christine Hoepfner, focava em utensílios de chá escavados em locais de Annapolis. Uma terceira exposição, também montada por Christine Hoepfner, continha cerâmicas do sítio da Thomas Hyde House e era uma demonstração da análise de cerâmica que acabamos de descrever. Os visitantes eram direcionados de qualquer exposição para as outras por uma série de panfletos projetados e escritos por Christine Hoepfner. Cada um desses panfletos também serviu para reforçar a mensagem da coleção em que estava disponível, reformulando-a e apresentando dados quantitativos que poderiam ser examinados posteriormente.

${ }^{20}$ Para os fins deste ensaio, a interpretação do sítio é apresentada como se guias arqueólogos fossem a única fonte de informação; na verdade, foi dividido entre uma apresentação oral e quatro cartazes de 400 palavras postados no sítio.

${ }^{21}$ As escavações no sítio da Shiplap House foram supervisionadas por Donald K. Creveling, auxiliadas por Paul A. Shackel. A visita ao local foi dirigida por Nancy J. Chabot (State University of New York em Binghamton), assistida por Kristen Peters. Eles, juntos com Simon Coleman, Matthew Johnson, Barbara Lichock, Barbara Ray, Ellen Saintonge, Patrícia A. Secreto, Helen Sydavar, Raymond Tubby e Patrícia
} 
Arqueologia que não sabia antes de visitar o sítio?". As respostas a esta pergunta se enquadram em três categorias amplas:

1. Respostas que mostram os visitantes percebendo que os arqueólogos escavam para responder perguntas, sugerindo uma compreensão de que os dados arqueológicos, como quaisquer dados históricos ou científicos, são coletados a partir de um ponto de vista específico - um dos insights mais importantes e mais acessíveis da Teoria Crítica.

2. Respostas que mostram os visitantes reconhecendo que a Arqueologia envolve mais do que escavações, descobertas e artefatos. Alguém que afirma ter aprendido sobre a "conexão da Arqueologia com o comportamento" pode muito bem ter aprendido como desafiar a percepção popular tradicional de que a Arqueologia trata de objetos. A habilidade de desafiar um entendimento dado como certo é a habilidade que esperamos cultivar nos visitantes e fazer com que eles apliquem isso a outros aspectos de suas vidas.

3. Respostas que mostram os visitantes compreendendo a Arqueologia como relevante para os dias de hoje. Em um nível, essas respostas são como aquelas discutidas anteriormente, sugerindo uma capacidade de desafiar a ideia de que os arqueólogos desenterram coisas antigas, não conectadas aos dias de hoje, por qualquer outra coisa que não seja seu valor curioso. No entanto, no contexto de nossa excursão pelo sítio Shiplap House, que lida com as origens de alguns aspectos da vida contemporânea, normalmente não examinados, o reconhecimento da relevância da Arqueologia para hoje pode indicar uma vontade de desafiar a inevitabilidade de alguns dos fundamentos da vida contemporânea.

Essas caracterizações das respostas dos visitantes aos nossos passeios são extraídas de mais de 1.000 avaliações que coletamos em cinco temporadas. Várias conclusões amplas podem ser tiradas desse corpo de dados. Em primeiro lugar, não precisamos simplificar a fala diante dos visitantes; podemos discutir ideias em vez de colher de pedreiro, estratigrafia, fragmentos de cerâmica ou buracos no solo. Além disso, o fato de um número surpreendente de visitantes estar disposto a escrever respostas longas e detalhadas às perguntas do formulário de avaliação, significa que as pessoas veem o sítio como um ambiente educacional e estão dispostas a nos deixar ensiná-las, em vez de simplesmente entretê-las. Passando do prático para o teórico, parece claro que os visitantes veem a Arqueologia Histórica como capaz de ensiná-los sobre as raízes da vida contemporânea. No entanto, quando os visitantes dizem que a Arqueologia é relevante para hoje, porque mostra "a continuidade da evolução em nossos dias", eles demonstram, além do surgimento da consciência crítica, a força e a incorporação do conceito de evolução como uma metáfora cultural para mudança a longo prazo. Como o conceito de evolução faz a mudança parecer inevitável e sua direção, além da agência humana, parece fornecer histórias para separações, isso pode não ser suficiente para tornar a ideologia local questionável. Para realizar o tipo de esclarecimento almejado pela Teoria Crítica, precisamos prestar atenção em como as pessoas pensam e não apenas no que pensam. Com as avaliações dos visitantes, aprendemos tanto sobre a possibilidade de lhes transmitir uma perspectiva crítica quanto sobre os obstáculos para adotá-la. Ainda não resolvemos todos os problemas de montar um programa público baseado na Teoria Crítica, mas a vontade demonstrada pelos

Walker, deram passeios a mais de 5.800 visitantes. Junto com o passeio, uma brochura de oito páginas, desenhada e editada por Nancy J. Chabot e Parker B. Potter, Jr., foi usada para apresentar a interpretação do sítio. 
visitantes em nos deixarem ensiná-los e a capacidade deles de aprender constituem um convite para continuarmos tentando.

\section{COMENTÁRIOS}

MICHAEL L. BLAKEY, Departamento de Sociologia e Antropologia, Howard University, Washington, D.C. 20059 , E.U.A. 20 XII 86.

As relações traçadas entre a variação crescente da cerâmica e padronização, a criação de novos modos à mesa ou "regras e divisões que diziam e mostravam aos indivíduos como se relacionar", e as divisões sociais mais amplas e alienações criadas pelo capitalismo demonstram, elegantemente, o valor de um paradigma parcialmente marxista. Da mesma forma, as dicotomias cidade/academia, negro/branco, residente/visitante, que emergem da análise crítica da "história" de Annapolis por Leone, Potter e Shackel, mostram como as divisões continuam a ser refletidas e socializadas para esses fins.

Eu questiono, entretanto, se esses resultados estão muito longe de conclusões baseadas em testes de hipóteses e replicabilidade. Dicotomias intimamente relacionadas foram mostradas nas representações históricas nos museus estaduais da vizinha Delaware e nos museus nacionais em Washington, D.C. (Blakey, 1983, 1986). Lá, as histórias contextualmente desconexas de negros, brancos e nativos americanos obscurecem a classe exploradora e as relações étnicas. Enquanto a história de Annapolis "fortalece" as reivindicações de residentes brancos "de poder político local," a descrição de Delawareans e americanos como definitivamente brancos é uma reivindicação em nível estadual e nacional.

Minha crítica a "Rumo a uma Arqueologia Crítica" é que este não realiza o que se propõe a fazer em termos mais fortemente marxistas. Do meu ponto de vista, da teoria marxista, a "emancipação", se preferir, é possibilitada pelo esclarecimento em relação aos interesses de classe e à exploração, anteriormente ocultos por uma "falsa consciência". Supõe-se que esses interesses também estão sendo exercidos pelos próprios cientistas. Duvido que os autores tenham revelado esses interesses de classe ou exploração em suas visitas guiadas. Eles parecem presumir que os turistas irão discernir seus próprios (individualistas?) "verdadeiros interesses" simplesmente com base no novo conhecimento de que a segmentação está sendo criada e que a Arqueologia pode demonstrá-la (na verdade, vender Arqueologia ao público parece ter sido mais importante do que aumentar a consciência sociopolítica). Os turistas reconhecerão que esses processos alienantes servem para sustentar o lucro de quem possui meios de produção e a exploração mais eficiente dos trabalhadores? Eu penso que não. Por que eles não deveriam atribuir a segmentação à "modernização" ou à evolução Spenceriana? $\mathrm{Na}$ verdade, os autores sugerem essa fraqueza em seus comentários finais, mas acho que esse problema é muito mais do que atenção inadequada a "como as pessoas pensam". A negligência da dialética de classe, deixando o papel da classe capitalista inexplicado, mina a tentativa de "emancipação".

O problema também pode estar embutido em suposições subjacentes: a abordagem (de acordo com Althusser, 1969,1971b; ver também Schwartzman \& Siddique, 1986) é fundamentalmente positivista, visando um conhecimento que é apolítico ou neutro e, consequentemente, produz resultados ostensivamente despojados de seu significado político. Althusser se opõe falsamente a ciência (autocrítica, aberta e capaz de produzir conhecimento real) à ideologia (dogmática, fechada e capaz de obscurecer a realidade). No entanto, 
são intrínsecas à ciência as suposições despercebidas, fechadas à crítica, precisamente quando parecem mais objetivas e evidentemente "reais". Pode-se dizer que a adesão ao empirismo ou positivismo às vezes foi ideológica, embora científica.

A Arqueologia Crítica, em vez de mostrar "relacionamentos reais" ou produzir "conhecimento menos contingente", pode apenas produzir conhecimento e relacionamentos contingentes de maneira diferente. A maneira como se define "emancipação" se refletirá no tipo de consciência que se produz pela pesquisa que nela se pretende criar, e a perspectiva sociopolítica do pesquisador influencia essa definição.

Este artigo demonstra a utilidade da Teoria Crítica sob essas restrições. Não segue adiante com uma formulação de implicações políticas claras que possam quebrar os laços de uma ideologia burguesa difusa. Além disso, a Teoria Crítica deve fomentar a crítica contínua por parte de seus próprios praticantes. A ciência é mais materialista, eu argumentaria, quando é mais crítica, isto é, quando é entendida como subjetiva de maneiras significativas e quando, portanto, a subjetividade parcial de um fato pode ser explorada e declarada. Isso não é encorajado por reivindicações de emancipação abstrata ou pelos procedimentos objetivos necessários para produzi-la. A Arqueologia Crítica seria profundamente crítica se pudesse lidar com os significados e as aplicações da subjetividade intrínseca no conhecimento científico. No entanto, concordo com Wylie (1986) que um meio de obter a verdade objetiva no absoluto continua sendo um ideal persistentemente intrigante que devemos continuar a explorar.

RICHARD BRADLEY, Departamento de Arqueologia, University of Reading, Reading, Reino Unido. 16 XII 86.

Não há razão para contestar a conclusão principal deste artigo de que as interpretações arqueológicas do passado e, em particular, sua apresentação ao público, são influenciadas pelas crenças e atitudes daqueles que as propõem. Isso ficou óbvio pela história do assunto e pelos ambientes sociais em que emergiu como uma disciplina independente (cf. Kristiansen, 1981). A Teoria Crítica fornece uma base mais rigorosa para este trabalho, mas a perspectiva básica não é inteiramente nova.

Existem certas dificuldades em defender esta posição. Se todo conhecimento do passado é produto de seu próprio tempo, é difícil ver como os estudiosos cujo trabalho é informado pela Teoria Crítica escaparão das suposições ocultas que afetam outras pessoas. Eles estão em posição de testar suas ideias de forma mais convincente do que qualquer outra pessoa? Em caso afirmativo, não é evidente em seus escritos até o momento. Se, por outro lado, estão fazendo declarações essencialmente políticas, podem diferir de outros investigadores apenas na franqueza com que admitem fazê-lo. Precisamos ser informados com bastante clareza se a Arqueologia Crítica é um meio de ação política e, em caso afirmativo, que forma deve assumir.

Esses problemas não são resolvidos no presente artigo, com o resultado que seu tom parece um pouco condescendente. Por que deveriam os visitantes de Annapolis ser vítimas tão crônicas de falsa consciência, incapazes de pensar por si mesmos sem a ajuda de arqueólogos? Todos são tolos da ideologia, exceto o acadêmico? O tom da conversa no sítio é bastante revelador. O relato das visitas de George Washington a Annapolis é muito condescendente, enquanto a discussão sobre "segmentação e padronização" é desnecessariamente obscura para aqueles que são novos na Arqueologia teórica.

Este artigo não consegue convencer o leitor do valor de uma Arqueologia Crítica, simplesmente porque as ideias que ela expressa dificilmente são arqueológicas. Estas devem sua origem a evidências documentais e a 
ideias do grande historiador francês Braudel. Teria sido revelador ver um estudo de caso que se baseou mais diretamente no registro arqueológico. Neste artigo, a Arqueologia está simplesmente fornecendo um colorido local para uma interpretação que poderia ser discutida de maneira perfeitamente adequada com base em fontes escritas. Há uma "lacuna de credibilidade" entre o grande quadro teórico e a exibição de escovas de dente históricas. A Arqueologia Histórica foi descrita como "uma maneira cara de descobrir o que já sabemos". Esse comentário costuma ser injusto, mas, neste caso, tem alguma justificativa.

BRIAN DURRANS, Museu da Humanidade, Burlington Gardens, Londres WIX 2EX, Inglaterra. 24 XII 86ª

Leone et al. prestam atenção insuficiente às condições passadas ou presentes em que o poder político é exercido.

Ao interpretar parte do registro arqueológico da histórica Annapolis, eles invocam o desenvolvimento do capitalismo industrial como um processo chave de estruturação. Este trabalho empírico convida à comparação com outros corpos de evidência. Por exemplo, o material escavado local usado para sugerir uma conexão entre um novo padrão de etiqueta doméstica e incorporação cultural no capitalismo precisa ser suplementado com dados históricos adicionais de Annapolis e de outros lugares se quisermos entender (e, por sua vez, generalizar) o caminho pelo qual esses dois sistemas eram articulados por relações sociais específicas entre diferentes classes. Manter o controle social na transição para uma nova forma de economia afeta as pessoas de maneiras diferentes, de acordo com seus papéis ocupacionais e outros. No caso pioneiro do norte da Inglaterra, argumentou-se que o controle foi alcançado a partir do bloqueio de subculturas potencialmente subversivas; com o efeito de minimizar a sensação de perda de controle sobre seu próprio trabalho, os trabalhadores estavam saturados com os valores culturais de seus empregadores (Foster, 1974, p. 22-27). Na ausência de dados arqueológicos sobre a classe trabalhadora da histórica Annapolis para indicar como o controle foi administrado ali, uma visão mais abrangente de como a ordem capitalista foi estabelecida e mantida por meio de uma canalização apropriada do poder político requer uma contribuição de outras fontes.

Os autores afirmam que os consumidores atuais de informações arqueológicas e históricas são encorajados a questionar suposições sobre suas próprias vidas, percebendo a ligação entre as mudanças anteriores na cultura doméstica (como a comensalidade) e o crescimento do capitalismo. Mais pertinente para a compreensão da histórica Annapolis é entender como funcionava o sistema de controle social local. Como funciona hoje é igualmente pertinente para uma estratégia contemporânea de disseminar novas visões do passado que podem potencialmente subverter a ideologia recebida e, assim, ajudar a abrir o tipo de emancipação que os autores parecem favorecer.

Criticando o que Leone et al. veem como viés ideológico na maneira como o capitalismo foi obscurecido nas representações padrão da história local, os autores substituem um preconceito próprio em seu tratamento inadequado do poder político. Eles observam que, em alguns ambientes, a Arqueologia é usada para servir a objetivos políticos, mas falham em mostrar como a política está profundamente enraizada nas práticas arqueológicas e em outras práticas culturais. Isso enfraquece sua resposta à distorção ideológica do passado. É relativamente fácil demonstrar que representações particulares do passado são distorções que servem clara ou dissimuladamente a interesses setoriais; decidir como responder a isso é mais difícil. Uma vez que os interesses da classe dominante são atendidos por conjuntos inteiros de categorias, bem como por argumentos específicos 
dentro delas, segue-se que neutralizar distorções do passado envolve uma crítica mais abrangente da atual organização do conhecimento e, em última análise, do sistema de poder político sustentado por isto.

Leone et al. reconhecem que uma teoria que expõe distorções ideológicas do passado e as situa em um contexto mais amplo equivale a uma crítica social ativa. Portanto, está sujeita a um critério de relevância ou acionabilidade - ou seja, uma estratégia para decidir como um relativismo, de outra forma exponencial, pode ser evitado e que objetivos específicos são alcançados. É improvável que o debate introspectivo entregue muito mais do que um novo conjunto de autoridades profissionais cujo radicalismo confirma as noções convencionais do avanço do conhecimento arqueológico por sucessivas mudanças de paradigma ao mesmo tempo em que deixa incontestada a posição contenciosa deste e de outros assuntos nas estruturas mais amplas da sociedade. Para a maior parte da Arqueologia contemporânea, o que é tratado como o contexto relevante para as discussões sobre ideologia é composto de teorias que reivindicam inspiração do marxismo, geralmente por meio de revisão ou rejeição, e de práticas representacionais destinadas a um público mais amplo. Exceto pelo fato de ser dividido por classes e outros critérios e que o poder dominante é exercido hegemonicamente em um sentido gramsciano, o caráter do contexto social no qual a Arqueologia é realizada é dado como certo, em vez de analisado em detalhes (Miller \& Tilley, 1984; Spriggs, 1984; Leone, 1981b).

Esta definição implícita de "relevância" foge do principal problema da prática de uma Arqueologia Crítica, que é: como promover a consciência do passado mudando a estrutura institucional que reflete a classificação social particular do conhecimento e suas atividades associadas às características do capitalismo tardio ao mesmo tempo que reconhece que os arqueólogos críticos não podem operar em ideias apenas, mas precisam ser empregados dentro dessa estrutura a fim de projetar seus argumentos. Este problema não pode ser resolvido dentro das formas tradicionais de academia. Enquanto a agitação apimentou a dieta educacional da Arqueologia acadêmica ao longo dos anos, a estreita integração da vida cultural, política e econômica alcançada nos países capitalistas avançados sugere que, apenas em combinação com uma organização coletiva mais eficaz e consciente, os argumentos intelectuais podem adquirir um impacto apropriado no poder político e econômico que interfere na disciplina.

Mesmo no âmbito da Arqueologia, dispositivos como os descritos por Leone et al. para sensibilizar os visitantes do sítio sobre o impacto do capitalismo na vida material são frágeis em comparação com a mídia dominante, por meio da qual visões ideológicas do passado são promovidas tanto na profissão quanto entre o público em geral. Este, certamente, não é um argumento para abandonar os esforços atuais, mas levanta agudamente a questão de como mesmo uma Arqueologia completamente radicalizada - quanto mais uma tendência minoritária - pode se articular com os conflitos sociais maiores que a envolvem.

Leone et al. afirmam que a escola de Frankfurt, Lukacs e Gramsci são importantes para seu conceito de Teoria Crítica, mas não dizem por quê. Quanto ao motivo de terem deixado Lênin de fora, uma pista é a opinião deles de que a adaptação de Marx às circunstâncias do século XX "começou com a escola de Frankfurt ... nos anos 1920". Isso é certamente incompatível com a visão usual do marxismo como um movimento político e também como uma corrente de pensamento. É claro que não seria razoável esperar que os autores apresentassem em um pequeno artigo seu próprio programa de Arqueologia nas condições atuais, mas isso não é desculpa para tratar tão superficialmente a herança intelectual que alegam, mesmo que ajude a explicar o uso que eles fazem disso, apresentando apoliticamente aquilo que eles argumentam serem questões inerentemente políticas. 
JOAN M. GERO, Departamento de Antropologia, University of South Carolina, Columbia, S.C. 2920 8, E.U.A. 31 XII 86.

A força deste trabalho é um exemplo claro, embora abreviado, de uma aplicação da Teoria Crítica à Arqueologia. Vários outros pesquisadores, amplamente revisados por esses autores, já apontaram uma série de restrições contextuais que afetam a objetividade do relato arqueológico, e Wylie (1985) ofereceu um relato lúcido dos preceitos da Teoria Crítica com suas aplicações para reconstrução arqueológica. Este artigo sobrepassa trabalhos anteriores, sugerindo formas específicas de análise arqueológica que geram uma compreensão "emancipatória" e colocam nossas vidas presentes em uma nova perspectiva, mostrando como a pesquisa arqueológica e as lições dela derivadas podem ser usadas para reeducar o público, especialmente no que diz respeito a maneiras pelas quais o passado subscreve a ideologia atual. Em ambos os aspectos, Leone et al. são bem-sucedidos e este resumo de seu projeto arqueológico fornece referências suficientes para explicações mais completas dos aspectos teóricos e metodológicos da obra para que os leitores interessados possam acompanhar.

A questão que gostaria de examinar mais de perto é se as ideias abrangidas por uma abordagem crítica da Arqueologia se limitam à Arqueologia Histórica. A base para sugerir que talvez apenas estruturas históricas possam ser abordadas "criticamente" é o argumento de que os estudos do passado devem fornecer insights sobre as circunstâncias atuais ou iluminar relações obscuras que existem hoje; presumivelmente, a lógica e a ideologia do sistema social atual são muito evoluídas ou muito distantes dos contextos pré-históricos para serem iluminadas por eles. Essa visão ignora, entretanto, o fato de que as relações ideológicas que a Arqueologia Crítica pode iluminar e o conhecimento que ela pode produzir não emergem de uma forma simples ou direta de uma inspeção de dados históricos. Em vez disso, os resultados de tais estudos são construídos no presente, por arqueólogos contemporâneos que combinam os dados com suas hipóteses e interpretações. O passado, então, pode ser usado para reestruturar entendimentos do presente ou para minar a ideologia prevalecente e indicar os grupos de interesse mais bem servidos por reconstruções particulares apenas na medida em que os arqueólogos contemporâneos possam se libertar de tal ideologia e formular reconstruções alternativas testáveis e convincentes. Além disso, uma iluminação das relações atuais, mesmo na estrutura mais "emancipatória", não constitui por si só um critério para validação de afirmações de verdade sobre o passado, um aspecto da Teoria Crítica que é deixado subespecificado neste artigo.

Uma reinterpretação radical do passado arqueológico, especialmente aquele que aponta o controle sobre grupos de interesse em diferentes escalas de operação, depende, então, (1) da liberdade de uma ideologia dominante que permite reconhecer outras dimensões da dinâmica social que se refletem na cultura material, e (2) das habilidades arqueológicas metodológicas e analíticas apropriadas. Nenhum dos pré-requisitos se aplica melhor aos dados históricos do que aos pré-históricos. Novas direções na análise de dados pré-históricos, como a identificação muito tardia de mulheres e trabalhos femininos na pré-história e a redefinição da complexidade cultural para incluir a análise de partes constituintes em vez de focar inteiramente na hierarquia, certamente devem ser reconhecidas como aplicações de uma "Teoria Crítica" à Arqueologia pré-histórica. 
G. P. GRIGORIEV, Bukharestskaya ul. 39 kor 1, kvartira 51, Leningrad F-7 I, U.R.S.S. 20 XII 86.

Do artigo de Leone, Potter e Shackel, aprendi muito sobre a segmentação de pessoas comendo e a segmentação de alimentos em serviços e por tipo, menos sobre três estratos sociais em Annapolis no terceiro quarto do século XVIII e nada em absoluto sobre a possibilidade de ver uma nova ordem de comportamento do ponto de vista da Arqueologia (não crítica). A descrição do manejo dos visitantes para sítios arqueológicos abertos (?) é de grande interesse, mas três linhas sobre os tipos e diâmetros dos pratos ao longo do tempo não são suficientes. Acho que não estamos longe do período de gestação de uma Arqueologia Crítica ${ }^{22}$.

IAN HODDER, Departamento de Arqueologia, University of Cambridge, Downing St., Cambridge CA2 3DZ, Inglaterra. 17 XII 86.

Os autores estão de parabéns por abrirem novos caminhos na análise das ideologias utilizadas pelos arqueólogos e por tentarem novas formas de apresentar o passado ao público em geral. Se a abordagem que eles estão usando deve ser descrita como "Teoria Crítica", talvez não seja uma discussão tão importante, mas vale a pena apontar que sua definição de Teoria Crítica é generosa. Às vezes, essa definição parece incluir a maior parte da teoria marxista contemporânea e, na avaliação das respostas dos participantes às excursões, os autores apresentam três pontos com os quais a maioria dos arqueólogos contemporâneos e curadores de museus provavelmente concordariam. Qualquer que seja o nome dado a essa abordagem, ela é atenciosa e bem-vinda.

Um problema levantado, no entanto, diz respeito ao grau de autorreflexividade envolvido. Pode-se esperar que uma abordagem que examina o trabalho dos arqueólogos como ideológico se volte para si mesma e se examine como ideológica. Na verdade, os autores preferem evitar essa questão, que certamente é difícil e estonteante, e apreendem um materialismo e positivismo muito semelhantes aos usados pela Nova Arqueologia. Certamente uma nova ortodoxia - baseada no marxismo - é proposta, mas substituir um conjunto de critérios "acordados" por outro dificilmente é muito crítico. A base ideológica da nova ortodoxia marxista nunca é exposta. Certamente não parece ter sido apresentada aos turistas de Annapolis.

A questão subjacente é se a realidade pode ser separada da ideologia. Os autores deixam clara sua posição em seu compromisso com o materialismo e com um positivismo "ajustado". Eles argumentam que os arqueólogos podem avançar em direção a um "conhecimento menos contingente" - isto é, conhecimento que é menos politicamente motivado do que muitos escritos arqueológicos hoje. Eles discutem o grau de validade que pode ser atribuído ao passado. Uma avaliação adequada dessa validade constitui esclarecimento. Tanto no passado quanto no presente, a ideologia é vista como um mascaramento da realidade objetiva. Assim, no passado, o capitalismo mercantil levou a um comportamento alimentar segmentado e padronizado e, no presente, o desejo por um tipo específico de turista em Annapolis levou a uma apresentação particular de George Washington.

Mas o que é essa realidade objetiva? Qual é essa base segura contra a qual a ideologia pode ser avaliada criticamente? Se for avaliada criticamente, parece escorregar para o ideológico. Por exemplo, os autores argumentam que o uso pela Academia Naval dos EUA de paredes e ruas foi ideológico na medida em que "parecia" separar a academia do resto da cidade. Na "realidade", a academia e a cidade estavam fortemente

\footnotetext{
${ }^{22}$ Os direitos autorais são retidos por Vsesoyusnoye Agentsvo po Avtorskim Pravam (6a, B. Bronnaya, K-104 Moscou 103670, U.R.S.S.).
} 
conectadas. No entanto, é difícil imaginar algo mais real do que paredes e ruas. Talvez elas formem a realidade e a hipótese dos autores de que conexões poderosas sejam ideológicas?

É "realmente" verdade que as mudanças na etiqueta alimentar podem ser vistas como produtos da ascensão do capitalismo mercantil? A ligação não é imediatamente óbvia e pode-se argumentar a favor de relacionamentos mais complexos. A interpretação dos autores envolve esclarecimento ou é simplesmente uma nova ideologia? Da mesma forma, a noção de que George Washington foi apresentado em Annapolis como um modelo ideal para o "turista de qualidade" é inteligente, mas talvez rebuscada; pode ser facilmente lida como ideológica.

Os autores não fazem nenhuma tentativa de examinar a base histórica de suas próprias teorias. Seu trabalho, portanto, permanece acrítico. Eles não revelam as estratégias sociais que estão seguindo ao defender conexões poderosas entre os vários segmentos da sociedade de Annapolis. Por que eles querem ver os costumes contemporâneos, e tomados como certos, ligados à ascensão do capitalismo? Por que eles desejam abraçar o materialismo e o positivismo?

Em um círculo acadêmico, os autores pelo menos declaram suas alianças, mesmo que não as examinem. Mas nas apresentações ao público, eles parecem não dar nenhuma indicação de "de onde vêm". A palestra no local parece uma nova ortodoxia, ela mesma além de qualquer crítica.

Felizmente, eu imagino que muitos turistas (talvez mais do que seus colegas acadêmicos, que são apanhados por um modo de discurso estabelecido) irão decidir sobre o que lhes é dito. Eles vão "ler" os eventos "reais", incluindo as palestras no local, à sua maneira. Assim, eles podem "ler" as evidências do aumento da segregação cultural e social para reforçar a visão de que o mundo contemporâneo escapou, pelo trabalho árduo, de um terrível socialismo comunal anterior. Ou podem até questionar que o uso de talheres padronizados é muito diferente do uso de tigelas comunitárias. Pode-se esperar que eles sejam capazes de colocar os especialistas acadêmicos em um contexto ideológico - "salvadores de nossa herança", "vermelhos", "cientistas inteligentes", "bobos" ou o que for. Se não puderem, então a necessidade de uma análise autocrítica é urgente.

JOSÉ LUIS LANATA, Programa de Estudos Pre-históricos, UBA-CONICET, Bartolomé Mitre 1970, 5A, 1039 Buenos Aires, Argentina. 19 XII 86.

A primeira crítica que pode ser feita a uma Arqueologia Crítica é que ela pode ser aplicada apenas a períodos de tempo para os quais temos fontes escritas. É neles que podemos ver, ou tentar ver, algo das ideologias dos grupos com os quais estamos trabalhando. Não consigo enxergar como isso poderia ser aplicado, por exemplo, a um grupo de caçadores-coletores americanos de 800, 1.500 ou 10.000 anos atrás, ou mesmo a um grupo Mochica. Na verdade, tenho a impressão de que o dado escrito está sendo considerado acriticamente "confirmado" pelo arqueológico, sem a menor tentativa de comparar os dois registros. Pareceme que uma Arqueologia Crítica não pode explicar nada mais do que deseja ver.

As visitas guiadas e os questionários para os participantes são uma ideia interessante, mas suspeito que muitas outras respostas foram omitidas aqui por razões de espaço. As respostas dos visitantes muitas vezes podem ser muito úteis, às vezes, talvez sem que desejemos, dando-nos ideias para o nosso trabalho. Devemos, entretanto, ter em mente que, ao explicar o sítio em termos de uma teoria particular, o guia turístico está indubitavelmente induzindo os visitantes a responder em termos semelhantes, ainda mais quando a maioria dos participantes de um passeio pode estar pouco acostumada à discussão teórica. 
Adotar uma abordagem que Leone et al. propõe em diferentes estudos pode ser interessante, tendo em vista as limitações que apontei; mas não vejo, no momento, como a Teoria Crítica pode nos ajudar a entender o passado com o qual trabalhamos diretamente. É claro que pode nos ajudar a entender certos eventos que estão ocorrendo hoje, especialmente nos países do Terceiro Mundo.

THOMAS E. LEVY e NEIL A. SILBERMAN, W. F. Albright Institute of Archaeological Research (Levy), P.O.B. 19096, 91110 Jerusalém, Israel. 14 I 87.

Leone e seus colegas devem ser elogiados por apresentarem uma declaração extremamente útil e coerente sobre a natureza da Teoria Crítica e sua aplicação à disciplina de Arqueologia. Embora tenham devidamente desafiado os arqueólogos em todo o mundo a considerar as implicações políticas e a ideologia embutida nas interpretações arqueológicas, talvez seja possível perguntar se, em contraste com a Arqueologia positivista, a Teoria Crítica pode realmente fornecer "conhecimento menos contingente" ou se, na verdade, fornece uma ideologia alternativa. Ao fazer uma abordagem crítica da etnografia e da história social de Annapolis, Maryland, Leone et al. obviamente fizeram uma contribuição significativa para a metodologia e o envolvimento social de arqueólogos históricos nos Estados Unidos. A questão que permanece, no entanto, é esta: a agenda educacional e acadêmica da Teoria Crítica em um lugar relativamente plácido como Annapolis pode ser facilmente transferida para regiões menos pacíficas? O que, por exemplo, os autores considerariam ser as implicações finais do uso da Teoria Crítica em campos minados arqueológicos, como o sul da África ou o Oriente Médio?

ROBERT PAYNTER, Departamento de Antropologia, University of Massachusetts, Amherst, Mass. 01003, E.U.A. 2 I 87.

Leone e seus colegas nos desafiam a levar a Arqueologia a sério como uma ciência da/para a sociedade. Seu foco está nas relações humanas, significados e objetos materiais que a cultura dos Estados Unidos dá como garantidos. Eles investigam uma ciência da sociedade estudando separações, incluindo aquelas encontradas em Annapolis entre negros e brancos, visitantes e residentes, a cidade e a Academia Naval, e a separação mais geralmente interessante entre o cientista e a sociedade.

Ao detalhar a mudança de material em Annapolis, Leone et al. identificam padrões materiais familiares no registro histórico da América do Norte - aumento exponencial na cultura material e na hierarquia e simetria na ordem desses objetos. Em suma, a Arqueologia Histórica documentou, nos termos de Foucault, um crescimento disciplinado no mundo material. Além de adicionar Annapolis aos casos agora familiares de Middle Virginia e New England, Leone et al. trazem um ângulo interpretativo distinto. No sistema de relações entre significados e objetos, os objetos são geralmente concebidos como passivos, como a precipitação de estruturas profundas ou como os subprodutos do comportamento humano. Para Leone et al., os objetos resultam de, e, mais importante, criam significado e comportamento. O fato de que os alimentos são consumidos de maneira disciplinada e que as viagens decorrem de maneira bem organizada contribuem para a criação de um novo sentido geral de mundo. Esse novo sentido também permite que o trabalho seja disciplinado e que uma visão diferente de gênero apareça. Em vez de estimular a resistência e a estagnação cultural, essas novas rotinas de trabalho e relações humanas fazem sentido para as pessoas, e o resultado é conformidade e mudança cultural. 
Em suma, Leone et al. produziram um estudo teórico e empírico sério da cultura material americana e suas relações com a mudança cultural.

Duas linhas de desenvolvimento adicional vêm à mente. Eu gostaria de ouvir mais sobre agentes dissidentes e elites. As separações descritas parecem ser aquelas que a nova elite gostaria que fizessem sentido. Especialmente nos primeiros períodos, quando essa ordem não estava totalmente desenvolvida ou manifesta, deve ter havido dissensão. Qual foi a ordem dos dissidentes e como eles fizeram uso (ou abusaram) de objetos materiais? Um segundo pensamento diz respeito aos índices de diversidade: este artigo mostra porque devemos usá-los e sugere que alguém deve reservar um tempo para revisar a literatura relevante em teoria da informação e ecologia para que possamos evitar a reinvenção da roda.

A separação mais importante para todos os antropólogos é a separação do cientista social da sociedade. A noção ingênua de que os cientistas estão separados da sociedade, observando sem participar, ainda prevalece e é especialmente desanimadora quando encontrada em pessoas treinadas no holismo da Antropologia. A Teoria Crítica, como uma abordagem para entender como os cientistas interagem com a sociedade, tem o potencial de produzir uma comunidade científica esclarecida e capacitada. Muito na etnografia interpretativa e na Arqueologia simbólica e estrutural reconhece essa relação. O que a Teoria Crítica sugere de maneira distinta é que um cientista responsável deve procurar capacitar membros não científicos da sociedade. Leone et al. delineiam ordenadamente como a Arqueologia em Annapolis pode ser usada para capacitar o público em relação à construção e controle do conhecimento sobre o passado e o presente. A interpretação cuidadosamente pensada e implementada da Arqueologia em Annapolis é um desafio para a profissão descobrir como capacitar o público em outras arenas. Um contrato de Arqueologia libertador ou um curso introdutório de Arqueologia emancipatório merece o mesmo pensamento longo e cuidadoso que Leone et al. deram ao trabalho no museu. Ao apresentar este desafio, os autores contribuíram para uma Arqueologia séria e autoconsciente, tanto para a sociedade quanto para ela.

MARIO A. RIVERA, Instituto de Antropologia e Arqueologia, Universidad de Tarapacá, Casilla 1611, Arica, Chile. 24 XII 86.

Ao comentar o trabalho de Leone et al., não se pode deixar de frisar que, por meio de exemplos como este, a Arqueologia adquire consequência e complexidade de olhares humanos que, ao se tornarem não $o$ passado, mas, sim, acontecimentos, assumem relevância e força. Este sentido da Arqueologia, que rigorosa e metodicamente empregado pode levar a uma forma diferente, ou pelo menos alternativa, de fazer ciência, é apropriadamente destacado como um dos desenvolvimentos de tempos muito recentes. A Arqueologia Crítica é de fato uma corrente que pode produzir contribuições importantes para o campo da interpretação e aplicação.

Pelo que aprendi sobre a Arqueologia andina, concordo com os autores sobre a rejeição de uma ordem de classificação das relações causais e sobre a criação de vínculos entre a realidade material e sua consciência. Enfatizar o "como" e investigar metodicamente os processos de desenvolvimento é fundamental. Por mais informações que tenhamos, como é o caso do mundo andino, por exemplo, para compreender de dentro os verdadeiros valores culturais de grupos que são os depositários de uma experiência diferente, a relação entre esta criativa ou (nas palavras dos autores) "esclarecedora” contribuição e qualquer ação social e/ou ideológica particular permanece uma questão em aberto. Portanto, esta tarefa deve ser muito bem compreendida quanto aos seus objetivos básicos. Explicar uma realidade cultural em termos de aspectos políticos e ideológicos 
externos a ela tenderia a reduzir a autenticidade do processo, ao passo que conseguir descobrir valores e ideologias de dentro contribuiria para uma explicação alternativa. A ideologia certamente supõe contradição, mas para ser criativa ela deve ser buscada de dentro. É, obviamente, na interpretação da história das ideias que reside o futuro desenvolvimento da Arqueologia e da Antropologia, e o artigo de Leone et al., com seu exemplo de Annapolis, contribui magnificamente para a teoria do problema.

ALISON WYLIE, Departamento de Filosofia, University of Western Ontario, London, Ont., Canadá N6A 3K7. 18 XII 86.

A Teoria Crítica é construída em termos muito amplos na discussão de Leone, Potter e Shackel. Ela não se restringe à " Teoria Crítica" associada à escola de Frankfurt ou, mais tarde, a Habermas, mas abrange qualquer programa de pesquisa que adote uma atitude criticamente autoconsciente em relação às pressuposições constituintes: conforme eles a descrevem, "a Teoria Crítica pergunta sobre qualquer conjunto de conclusões a partir de que ponto de vista são construídas". Pressionar por tal reflexividade é crucialmente importante, mas uma série de coisas importantes são deixadas de lado ou não são especificadas quando a " Teoria Crítica" é interpretada de maneira tão ampla. Por exemplo, qual é o ponto de vista do teórico crítico e a quais critérios de aceitabilidade o exercício de desmascaramento responde? Que tipo de comentário o desmascaramento fornece sobre os contextos contemporâneos, e como determinar quando é acurado no que revela sobre as condições e interesses que informam a prática? Leone et al. param no ponto no qual surgem as perguntas mais interessantes e difíceis. Isso não é culpar sua análise ou recomendações, mas sugerir alguns possíveis caminhos importantes para o desenvolvimento de sua iniciativa crítica que ainda precisam ser explorados.

O ponto de vista da crítica de Leone et al. gira em torno da rejeição do objetivismo em um sentido muito amplo. Ao longo das linhas recentemente sugeridas por Bernstein (1983, p. 8), entre outros: eles negam centralmente a plausibilidade de qualquer posição que presuma a existência de contexto - princípios transcendentes e a-históricos de racionalidade ou aceitabilidade em termos dos quais a eficácia de reivindicações de conhecimento concorrentes pode ser julgada. Bernstein caracteriza o relativismo como qualquer posição que, ao rejeitar o objetivismo, reconhece uma pluralidade de princípios legítimos de método, racionalidade ou escolha de teoria; o relativismo, por esse motivo, incluiria sua própria opção hermenêutica, que, ele sugere, promete um caminho "além do objetivismo e do relativismo". Ele pressiona essa concepção de relativismo em oposição a uma definição estreita que presume que a rejeição de uma estrutura categorial acarreta uma falta anarquista de quaisquer padrões governantes de ação ou princípios de escolha de teoria; esse é o tipo de consequência relativista que normalmente alimenta a busca por fundamentos em face de repetidos fracassos que sugerem a futilidade de qualquer empreendimento.

O ponto de Bernstein e de vários comentaristas sobre o fim dos projetos do Iluminismo é que o abandono da busca por fundamentos absolutos não impede uma avaliação crítica, mesmo baseada em princípios, de reivindicações de ação e conhecimento. Deve-se simplesmente reconhecer que a validade dos princípios envolvidos é interna a um contexto particular e que eles próprios são provisórios, em evolução, e objetos adequados de avaliação crítica. Isso parece capturar a posição articulada no presente artigo. Diante disso, as propostas de Leone et al. para ação prática seguem diretamente. Os consumidores de relatos históricos e arqueológicos do passado devem ser conscientizados de forma plena e explícita de que esses são, de fato, 
construções cuja credibilidade depende de um determinado quadro de referência: padrões de racionalidade, "interesse", "ponto de vista".

Mas parar com isso é deixar os arqueólogos e, de fato, os consumidores de seus construtos sem qualquer ideia clara de quais princípios mais amplos (embora ainda específicos do contexto, em evolução) sustentam o ponto de vista da crítica. As análises desenvolvidas a partir deste ponto de vista (por exemplo, da histórica Annapolis) não são oferecidas como opinião arbitrária, apesar de estarem abertas a reavaliação. Leone et al. não endossam o niilismo associado à definição restrita de relativismo, um niilismo que alimenta a apatia política com tanta certeza quanto o dogmatismo. Eles parecem responder a essa preocupação quando sugerem que a prática crítica se engaje em um "ajuste" dos padrões positivistas às "realidades dos dados arqueológicos". O positivismo é, no entanto, uma teoria da ciência e do conhecimento fundamentalmente objetivista e, portanto, antitética à consciência crítica e reflexiva das possibilidades plurais de construção do conhecimento que Leone et al. endossam.

Uma alternativa que pode se apropriar de alguns dos métodos desenvolvidos nas ciências empíricas não reflexivas que os positivistas adotaram para definir todas as práticas científicas legítimas (métodos analíticoempíricos, como Habermas os descreve) e colocá-los a serviço de objetivos emancipatórios críticos. Isso, entretanto, não deixará tais métodos inalterados; se eles são genuinamente para servir a objetivos emancipatórios, seu próprio status contingente deve ser explicitamente reconhecido, e eles devem estar sujeitos a revisão, restrições no escopo de aplicação, e correção à luz de outros métodos (por exemplo, hermenêutico, histórico). O resultado será uma forma diversificada e evolutiva de prática, inimiga das concepções positivistas da ciência. Se os métodos da ciência empírica-analítica existente não devem subverter os objetivos da prática reflexiva, parece essencial que o ponto de vista da crítica - seus objetivos e critérios de adequação provisórios e essencialmente pragmáticos - seja claramente articulado. Este pareceria, em qualquer caso, um requisito central do compromisso com a autoconsciência crítica.

\section{RÉPLICA}

MARK P. LEONE, PARKER B. POTTER, JR., e PAUL A. SHACKEL, Annapolis, Md. 21401, E.U.A. 6 II 87.

Agradecemos a todos os comentadores por levarem o nosso trabalho no espírito a que se destina. Não é nosso objetivo oferecer a última palavra sobre a aplicação da Teoria Crítica à Arqueologia, e os comentários mais de apoio, todos construtivos - servem admiravelmente para tornar a peça um ponto de partida na aplicação arqueológica da Teoria Crítica. Além de reconhecer nosso prazer com o tom positivo da maioria das respostas, gostaríamos de destacar vários pontos.

Lanata duvida da utilidade da Teoria Crítica para a Arqueologia pré-histórica. Deixamos o assunto em aberto, e nossa clara preferência é que seja resolvido afirmativamente por meio da criação de pré-histórias críticas. Gero fornece uma resposta a Lanata sobre este ponto, e aos seus argumentos podem ser adicionados os trabalhos de Handsman (1983, 1985, 1986) e Keene (1986), entre outros.

Lanata levanta uma segunda questão respondida por um colega comentarista: ele se pergunta se os visitantes são capazes de responder a uma apresentação em quaisquer termos diferentes dos usados nela, 
sugerindo que criamos a possibilidade de superestimarmos o aprendizado que ocorre. Concordamos que é difícil determinar o quanto de aprendizado ocorre quando os visitantes simplesmente repetem algo que acabaram de ouvir. Mas, como Blakey, ficamos muito mais preocupados quando os visitantes transformam as informações que ouvem em evidência para uma posição antitética do ponto de vista que informa uma apresentação, que ilustra o poder do capitalismo tardio de absorver, transformar e usar até mesmo uma radical crítica de si mesmo.

Uma área de preocupação para Wylie, Hodder, Blakey e Levy e Silberman é a relação entre a Arqueologia Crítica e a Arqueologia positivista tradicional. Wylie discute a relação entre relativismo e objetivismo enquanto Hodder discute ideologia e realidade. "Arqueologia em Annapolis" não é positivista, no sentido convencional, e pode não ser em nenhum sentido. Nossas conclusões são obtidas por técnicas e métodos que estão continuamente disponíveis para exame. Eles podem ser desafiados e desconstruídos, e às vezes são, pelos membros mais articulados e resistentes de nosso público. Portanto, a racionalidade de usar um conjunto de técnicas arqueológicas para examinar ou "testar" um conjunto de descrições ou "hipóteses" sobre o capitalismo mercantil é provisória e evoluiu ao longo de cinco anos e meio. Os desafios são parte do crescimento do projeto, assim como os métodos de tratamento dos dados.

Wylie e Hodder comentam sobre nossa ampla definição de Teoria Crítica e suas implicações para um programa de pesquisa. Concordamos com eles e reconhecemos que nossos pontos de vista individuais muitas vezes não são especificados, que o desmascaramento não é orientado diretamente para os interesses de classe e que o aparato do procedimento arqueológico é relativamente convencional. Somos transparentes sobre custos e patrocínios, status acadêmico e, às vezes, resultados arqueológicos inconsequentes de nosso trabalho imediato.

Paynter, Durrans e Blakey apontam, corretamente, a falta de uma análise de classe em nosso estudo de Annapolis. Russell Handsman também nos fez notar isso em várias ocasiões, em vários contextos diferentes ${ }^{23}$. Para seguir na direção indicada por muitos teóricos críticos, o melhor começo seria analisar as relações raciais em Annapolis. Annapolis tem a escravidão como parte de sua herança colonial; o ancestral de Alex Haley, Kunta Kinte, foi vendido na doca da cidade de Annapolis. A cidade teve nos séculos XVIII e XIX uma significativa população negra livre. Nos últimos dois anos, a cidade redesenhou seus limites políticos internos para criar uma ala adicional com maioria negra. A cidade ainda está em litígio com membros negros de sua força policial a respeito de promoção e outras questões. No início de 1987, funcionários negros do Hospital Geral Anne Arundel em Annapolis fizeram uma manifestação acusando o hospital de discriminação racial em várias áreas. Tudo isso é simplesmente para sugerir que a relação entre negros e brancos é uma questão política viva em Annapolis, com uma história que remonta aos dias coloniais. A questão é como criar uma Arqueologia que ilumine facetas significativas da história das relações raciais (e presumivelmente da dominação branca) em Annapolis, e para essa questão ainda não temos uma resposta firme.

Finalmente, nos encontramos em Annapolis em uma posição interessante. Enquanto muitos comentaristas acadêmicos sobre "Arqueologia em Annapolis" consideram nossas análises, interpretações e apresentações "suaves" quando comparadas aos requisitos da Teoria Crítica, alguns observadores em Annapolis acham o que temos a dizer muito estridente e político. Isso traz à tona a questão crucial citada por Wylie, Paynter, Hodder, Durrans e Bradley, a saber, a questão da autorreflexividade. Concordamos que, no artigo, não somos

\footnotetext{
${ }^{23}$ Handsman nos ajudou consideravelmente a refletir sobre a lógica de nosso artigo. A sugestão de que fosse escrito para CURRENT ANTHROPOLOGY veio de Henry Wright.
} 
adequadamente autorreflexivos. Durrans articula com bastante clareza a posição em que nos encontramos, dependentes do emprego de um sistema que desejamos criticar. Especificamente, "Arqueologia em Annapolis" é patrocinado e parcialmente financiado por uma organização de preservação privada local com alguns oponentes e detratores. Essa organização negligenciaria seus próprios deveres e interesses se não ficasse de olho em "Arqueologia em Annapolis" para se certificar de que o projeto não produz nada útil para seus oponentes. No geral, a Historic Annapolis, Inc. é muito mais tolerante com a autocrítica do que a maioria dos outros grupos de preservação bem conhecidos e tem uma capacidade maior de entender e, às vezes, até apreciar a autocrítica. Na necessidade de dar atenção às circunstâncias em que opera, "Arqueologia em Annapolis" não é de todo original. Qualquer projeto em Arqueologia Crítica - e na verdade qualquer projeto arqueológico está no centro de um conjunto de contextos que incluem, mas não se limitam, agências de financiamento e empregadores acadêmicos. As questões mais urgentes que os arqueólogos críticos enfrentam são, como Durrans entende, questões de prática.

\section{REFERÊNCIAS BIBLIOGRÁFICAS}

Althusser, L. (1969) For Marx. Nova York: Vintage.

Althusser, L. (1971a) ldeology and ideological state apparatuses. Lenin and philosophy. Traduzido do francês por Ben Brewster. Nova York: Monthly Review Press.

Althusser, L. (1971b) Lenin and philosophy. Nova York: Monthly Review Press.

Baldridge, H. A. (1928) Washington's visits to colonial Annapolis. Naval Institute Proceedings, Fevereiro.

Baranik, R., S. Bromberg, S. Charles, Worth, S. Cohen, C. Duncan, Gargagliano, S., Golden, E., Koenig, J., Kosuth, J., McCall, A., Pechter, P., Bendock Pelosini, E., Roseman, A., Rosing, L., Rousseau A. M., Wallach, A., Weissman, W., Durham, J. (1977) An anti-catalog. Nova York: Catalog Committee, Artists Meeting for Cultural Change.

Barnett, S., \& Silverman, M. G. (1979) Ideology and everyday life. Ann Arbor: University of Michigan Press.

Bernstein, R. J. (1983) Beyond objectivism and relativism. Philadelphia: University of Pennsylvania Press.

Blakey, M. L. (1983) Socio-political bias and ideological production in historical archaeology. Joan M. Gero, David M. Lacy, \& Michael L. Blakey (eds.). The socio-politics of archaeology: Department of Anthropology, University of Massachusetts, Amherst, Research Report 23, p. 5-16.

Blakey, M. L. (1986) American nationality and ethnicity in the depicted past. Trabalho apresentado no World Archaeological Congress, Southampton and London.

Brannigan, A. (1981) The social basis of scientific discoveries. Cambridge: Cambridge University Press.

Braudel, F. (1979a) The structure of everyday life: Civilization and capitalism, 15th-18th century. Nova York: Harper and Row.

Braudel, F. (1979b) The wheels of commerce: Civilization and capitalism, 15th-18th century. Nova York: Harper and Row.

Carr, L. G. \& Walsh, L. S. (1977) Inventories and the analysis of wealth and consumption patterns in St. Mary's County, Maryland, 1658-1777. Trabalho apresentado na Newberry Library Conference on Quantitative and Social Science Approaches in Early American History, Outubro 6-8.

Carr, L. G., Walsh. L. S. (s/d). Changing lifestyles and consumer behavior in the colonial Chesapeake. MS, Maryland Hall of Records. 
Carravetta, P. (1984) An interview with William Spanos. Critical Texts, v. 3, n. 1, p. 10-27.

Clarke, D. L. (1973) The past and the present in the present. American Antiquity, v. 50, p. 52-62.

Crosby, C. (1982) Excavations at the Victualling Warehouse Site, AN 14, 1982: Preliminary report. MS, Historic Annapolis, lnc.

Deetz, J. (1977) ln small things forgotten: The archaeology of early American life. Nova York: Doubleday.

Deetz, J. (1983) Scientific humanism and humanistic science: A plea for paradigmatic pluralism in historical archaeology. Geoscience and Man, v. 23(Abril 29), p. 27- 34.

Dent, R. J. (1985) Archaeological excavations at the Hammond-Harwood House, Annapolis, Maryland. Report prepared by Historic Annapolis, Inc., for the Hammond-Harwood House Association. MS, Historic Annapolis, Inc.

Detweiler, S. G. (1982) George Washington's chinaware. Nova York: Harry N. Abrams.

Eagleton, T. (1985-86) Marxism and the past. Salmagundi, n. 68-69, p. 271-90.

Feyerabend, P. K. (1970) Consolation for the specialist. Lakatos, I. e Musgrave, A. (eds.), Criticism and the wanting of knowledge. Cambridge: Cambridge University Press.

Foster, J. (1974) Class struggle and the industrial revolution: Early industrial capitalism in three English towns. Londres: Methuen. [BD]

Gero, J. M., David M. L., Blakey, M. L. (1983) The socio-politics of archaeology. University of Massachusetts Department of Anthropology Research Report 23.

Raymond, G. (1981) The idea of a critical theory. Cambridge: Cambridge University Press.

Glassie, H. (1975) Folk housing in Middle Virginia: A structural analysis of historic artifacts. Knoxville: University of Tennessee Press.

Handsman, R. G. (1980) The domains of kinship and settlement in historic Goshen: Signs of a past cultural order. Artifacts, v. 9, p. 2-7.

Handsman, R. G. (1981) Early capitalism and the center village of Canaan, Connecticut: A study of transformations and separations. Artifacts, v. 9, p. 1-21.

Handsman, R. G. (198-) The hot and cold of Goshen's history. Artifacts, v. 3, n. 20.

Handsman, R. G. (1983) Toward archaeological histories of Robbins Swamp. Artifacts, v. II, n. 3, p. 1-20.

Handsman, R. G. (1985) History and communal class struggles among early gatherer-hunters. Trabalho apresentado na annual meeting of the American Anthropological Association, Washington, D.C.

Handsman, R. G. (1986) How histories were made by hunter-gatherers, then disciplined, and finally made to disappear by us. Trabalho apresentado na 4th International Conference on Hunting and Gathering Societies, Londres, Inglaterra.

Handsman, R. G., \& Leone, M. P. (1989) Living history and critical archaeology and the reconstruction of the past. V. Pinsky e A. Wylie (eds), Critical Traditions in Contemporary Archeology: Essays in the Philosophy, History and Socio-Politics of Archeology. Cambridge, UK: Cambridge University Press, pp. 117-135.

Hodder, I. (ed.) (1982) Symbolic and structural archaeology. Cambridge: Cambridge University Press.

Hodder, I. (1984) Archaeology in 1984. Antiquity, v. 58, p. 25-32.

Hodder, I. (1985) Processual archaeology. Schiffer, M. B. (ed.), Advances in archaeological method and theory, vol. 8. Orlando: Academic Press. p. 1-26.

Hopkins, J. W. (1986) Preliminary report on excavations at the State House Inn, Annapolis, Maryland, 1985. MS, Historic Annapolis, Inc. 
Keene, A. S. (1986) Stories we tell: Gatherer-hunters as ideology. Trabalho apresentado na 4th International Conference on Hunting and Gathering Societies, Londres, Inglaterra.

Kehoe, A. B. (1984). The myth of the given. Trabalho apresentado na Society for American Archaeology, Portland, Abril.

Kristiansen, K. (1981) A social history of Danish archaeology (1805-1975). G. Daniel (ed.) Towards a history of archaeology. Londres: Thames and Hudson. p. 20-44.

Landau, M. (1984) Human evolution as narrative. American Scientist, v. 72, p. 262-68.

Latour, B., \& Woolgar, S. (1979) Laboratory life: The social construction of scientific facts. Beverly Hills: Sage.

Leone, M. P. (1981a) Archaeology's material relationship to the present and the past. Gould, R. A. e Michael B. Schiffer (Eds.), Modern material culture. Nova York: Academic Press, p. 5-14.

Leone, M. P. (1981b) The relationship between artifacts and the public in outdoor history museums. A. M. Cantwell, Nan Rothschild, and James B. Griffen (eds.) The research potential of anthropological museum collections. Nova York: New York Academy of Sciences, p. 301-13.

Leone, M. P. (1983) Method as message. Museum News, v. 62, n. 1, p. 35-41.

Leone, M. P., \& Parker B. Potter, Jr. (1984) Archaeological Annapolis: A guide to seeing and understanding three centuries of change. Annapolis: Historic Annapolis, Inc.

Lowenthal, D. (1985) The past is a foreign country. Cambridge: Cambridge University Press.

Lukacs, G. (1971) Reification and the consciousness of the proletariat. in History and class consciousness. Cambridge: M.I.T. Press. p. 83-222.

Mcguire, R. (1988) The dead need not speak: Ideology and the cemetery The recovery of meaning in historical archaeology. Mark P. Leone e Parker B. Potter, Jr. (Ed.) Washington, D.C.: Smithsonian Institution Press.

Meltzer, D. (1981) Ideology and material culture. Richard A. Gould e Michael B. Schiffer (eds.) Modern material culture. Nova York: Academic Press.

Middleton, A. P. (1953) Tobacco coast: A maritime history of Chesapeake Bay in the colonial era. Baltimore: Johns Hopkins University Press.

Miller, D. (1982a) Artifacts as products of human categorization process. Hodder, I. (ed.) Symbolic and structural archaeology. Cambridge: Cambridge University Press, p. 89-98.

Miller, D. (1982b) Explanation and social theory in archaeological practice. Colin Renfrew, Michael J. R e Barbara Abbott Segraves (eds.). Theory and explanation in archaeology. Nova York: Academic Press.

Miller, D. (1985) Ideology and the Harappan civilization. Journal of Anthropological Anthropology, v. 4, p. 1-38.

Miller, D., \& Tilley, C. (eds.) (1984) Ideology, power, and prehistory. Cambridge: Cambridge University Press.

Norris, W. B. (1925) Annapolis: Its colonial and naval story. Nova York: Crowell.

Papenfuse, E. (1975) In pursuit of profit: The Annapolis merchant in an era of the American Revolution, 1763-1805. Baltimore: Johns Hopkins University Press.

Patterson, T. C. (1984) Exploration and class formation in the Inca state. Trabalho apresentado na Canadian Ethnological Society, Montreal, maio.

Peet, R. J. (1975) lnequality and poverty: A Marxist-geographic theory. Annals of the Association of American Geographers, v. 65, p. 564-71.

Peet, R. J. (1977) The development of radical geography in the United States. Progress in Human Geography, v. 1, p. $240-63$. 
Peet, R. J., \& Lyons, J. V. (1981) Marxism: Dialectical materialism, social formation, and geographic relations. M. E. Harvey e B. P. Holly (eds.). Themes in geographic thought. Londres: Croom Helm. p. 187205.

Perper, T. \& Schrire, C. (1977) The Nimrod connection: Myth and science in the hunting model. Morley Kare e Owen Maller (eds.). The chemical senses and nutrition. Nova York: Academic Press.

Potter, P. B., Jr., \& Leone, M. P. (1986) History in museums: A critical capacity in museums versus repeating tradition. in Education: The spirit of the American museum. Mary Ellen M. e Stapp, C. (Ed), Journal of the Washington Academy of Sciences, 75(3).

Potter, P. B., Jr., \& Leone, M. L. (1984) Archaeology in public in Annapolis: Four seasons, six sites, seven tours, and 32,000 visitors. American Archaeologist, v. 6, n. 1, p. 51-61.

Riley, E. (1897) Souvenir volume of the state convention of Maryland firemen held at Annapolis, June 9, 1897. Annapolis.

Riley, E. (1901) Annapolis: "Ye ancient capital of Maryland". Annapolis: Annapolis Publishing Company.

Riley, E. (1906) Pictorial Annapolis, Anne Arundel, and the Naval Academy. Baltimore: King Brothers.

Riley, E. [1976] (1887) "The ancient city": A history of Annapolis in Maryland, 1649-1887. Annapolis: Record Printing Office (Anne Arundel-Annapolis Bicentennial Committee).

St. George, R. B. (1985) "Artifacts of regional consciousness, 1700-1780," in The great river: Art and society of the Connecticut Valley, 1635-1820, p. 29-39. Hartford: Wadsworth Atheneum.

Schwartzman, D. W., Siddique, M. (1986) How ideology relates to natural science with examples from geology and cosmogony. Science and Nature, v. 7/8, p. 101-11.

Shackel, P. A. (1986a) The creation of behavioral standardization and social segmentation in Anglo-America. Trabalho apresentado na Northeastem Anthropological Meetings, Buffalo, N.Y., março.

Shackel, P. A. (1986b) Archaeological testing at the Thomas Hyde House, 193 Main Street Site, 18 Ap 44, Annapolis, Maryland. MS.

Shanks, M., \& Christopher T. (1982) Ideology, symbolic power, and ritual communication: A reinterpretation of Neolithic mortuary practices. Hodder, I. (ed.), Symbolic and structural archaeology. Cambridge: Cambridge University Press. p. 129-54.

Shanks, M. \& Christopher T. (s/d) Studies in archaeological theory practices. Cambridge: Cambridge University Press.

Shennan, S. (1982) Ideology, changes, and the European Early Bronze Age. Hodder, I. (Ed.), Symbolic and structural archaeology. Cambridge: Cambridge University Press. p. 155-61.

Smith, A. (1937 [1776]). An inquiry into the nature and causes of the wealth of nations. Edited by Edwin Canaan. Nova York: (Modem Library) Random House.

Spriggs, M. (Ed.) (1984) Marxist perspectives in archaeology. Cambridge: Cambridge University Press.

Stevens, W. O. (1937) Annapolis: Anne Arundel's town. Nova York: Dodd, Mead.

Sweeney, K. M. (1984) Mansion people. Winterthur Portfolio, v. 19, p. 231-55.

Thomas, R. (1952) Washington's letters in Annapolis. Picket Post, v. 37 (July), p. 40-41.

Thorp E, 1. J. (1981) Anthropological orientations on astronomy in complex societies. Trabalho apresentado na Third Theoretical Archaeological Group Conference, Reading, U.K.

Tilley, C. (1982) Social formation, social structures, and social change. Hodder, I. (ed.), Symbolic and structural archaeology. Cambridge: Cambridge University Press. p. 26-38. 
Unger, R. M. (1976) Law in modem society: Toward a criticism of social theory. Nova York: Free Press.

Wallace, M. (1981) Visiting the past: History museums in the United States. Radical History Review v. 25, p. 63-96.

Wallace, M. (1984) Mickey Mouse history. Radical History Review, v. 32, p. 33-57.

Walsh, L. S. (1983) Urban amenities and rural sufficiency: Living standards and consumer behavior in colonial Chesapeake, 1643-1777. Journal of Economic History, v. 43, p. 81-104.

Wylie, A. (1985a) Putting Shakertown back together: Critical theory in archaeology. Journal of Anthropological Archaeology, v. 4, p. 133-47.

Wylie, A. (1985b) The reaction against analogy. Michael B. Schiffer (ed.), Advances in archaeological method and theory, vol. 8. Nova York: Academic Press.

Wylie, A. (1986) Matters of fact and matters of interest. Trabalho apresentado no World Archaeological Congress, Southampton e Londres.

Yentsch, A. E. (1983) Salvaging the Calvert House site. Final report for the N.E.H. Grant RO-20600-83. MS, Historic Annapolis, Inc.

Zannieri, P. A. (1980) Dancing pilgrims: The dynamics of museum interpretation. M.A. paper, Department of Anthropology, Brown University, Providence, R.I. 